\title{
WestVirginiaUniversity
}

THE RESEARCH REPOSITORY @ WVU

Graduate Theses, Dissertations, and Problem Reports

2016

\section{Water Permeability of New and Maximum Laundered Isolation Gown Cuffs}

Stacey Kamarec

Follow this and additional works at: https://researchrepository.wvu.edu/etd

\section{Recommended Citation}

Kamarec, Stacey, "Water Permeability of New and Maximum Laundered Isolation Gown Cuffs" (2016). Graduate Theses, Dissertations, and Problem Reports. 5926.

https://researchrepository.wvu.edu/etd/5926

This Thesis is protected by copyright and/or related rights. It has been brought to you by the The Research Repository @ WVU with permission from the rights-holder(s). You are free to use this Thesis in any way that is permitted by the copyright and related rights legislation that applies to your use. For other uses you must obtain permission from the rights-holder(s) directly, unless additional rights are indicated by a Creative Commons license in the record and/ or on the work itself. This Thesis has been accepted for inclusion in WVU Graduate Theses, Dissertations, and Problem Reports collection by an authorized administrator of The Research Repository @ WVU. For more information, please contact researchrepository@mail.wvu.edu. 


\title{
Water Permeability of New and Maximum Laundered Isolation Gown Cuffs
}

\author{
Stacey Kamarec
}

\author{
Thesis submitted \\ to the Benjamin M. Statler College of \\ Engineering and Mineral Resources \\ at West Virginia University
}

in partial fulfillment of the requirements for the degree of

\author{
Master of Science in \\ Industrial Hygiene
}

Steve Guffey, Ph.D., Chair

Selcen Kilinc-Balci, Ph.D.

Xinjian He, Ph.D.

Department of Industrial Management Systems Engineering

Morgantown, West Virginia

2016

Keywords: Isolation gowns, infectious diseases, cuffs, water permeability, barrier performance, healthcare workers

Copyright 2016 Stacey Kamarec 


\title{
ABSTRACT
}

\section{Water Permeability of New and Maximum Laundered Isolation Gown Cuffs}

\section{Stacey Kamarec}

\begin{abstract}
ANSI/AAMI PB70 "Liquid barrier performance and classification of protective apparel and drapes intended for use in healthcare facilities" sets barrier performance requirements for the classification of isolation gowns. Manufacturers voluntarily follow these requirements for gowns used in minimal and low risk situations but end users must decide which gown is most suitable for the required task. ANSI/AAMI PB70 classifies isolation gowns based on the level of barrier protection the gowns are expected to provide and recommends several tests to help manufacturers assign the levels to the gowns (1-4). Published literature has identified performance concerns of isolation gowns, but there are no studies that examine the barrier qualities of isolation gown cuffs. Therefore, it is the purpose of this study to examine isolation gown cuffs' resistance to water based on ANSI/AAMI PB70:2012 criteria using modified versions of a water impact penetration test and a hydrostatic pressure water resistance test. The investigator took samples from 6 models of gowns, three models within the Level 1 designation and three models from Level 2. Half of each sample group was washed and dried for one laundering cycle and the other half for the maximum recommended laundering cycles, prior to testing.
\end{abstract}

Water impact penetration testing was performed using a plastic funnel fixed $0.6 \mathrm{~m}$ above a clipboard at a 45-degree angle from the parallel to the floor. Specimen were clamped over-top a piece of blotter paper onto the clip board. Distilled water was poured into the funnel and allowed to spray on the specimen. The investigator weighed blotter paper before and after testing and the change in weight $(\mathrm{g})$ was reported. The hydrostatic pressure test was performed by securely clamping the cuff between two rings directly touching the surface of a reservoir of water. Water pressure in the reservoir was set to increase under the specimen at $60 \mathrm{mbar} / \mathrm{min}$ until water penetrated the fabric in 3 unique locations. The pressure of the third water droplet penetration (mbar) was reported. 
As expected, gown cuffs washed once allowed less water penetration than gown cuffs washed multiple times $(p<0.0001)$. Level 1 gown cuffs allowed more water penetration than Level 2 gown cuffs for the water impact penetration test $(p<0.001)$. There was no difference between barrier performance of Level 1 and Level 2 cuffs in the hydrostatic pressure test ( $p>0.05)$. According to ANSI/AAMI PB70, Level 1 gowns (body fabric only, not cuffs) must pass the water impact penetration test with a change in blotter paper no more than $4.5 \mathrm{~g}$. Only $20.8 \%$ of the cuffs from gowns given the Level 1 classification by manufacturers met this requirement. ANSI/AAMI PB70 specifies that Level 2 gown fabric could have a change in blotter paper weight of no more than $1 \mathrm{~g}$. Only $44.8 \%$ of cuffs belonging to gowns claimed to be Level 2 by manufacturers met this requirement. None of the cuffs from Level 2 gowns met theANSI/AAMI PB70 performance criteria for the hydrostatic pressure test for the gown fabric material.

Isolation gown cuffs are the only part of isolation gowns not considered as a critical zone for exposure by ANSI/AAMI. However, studies have shown that even with proper donning and doffing, gown cuffs do become contaminated which puts the user at risk for contact with infected blood and bodily fluids. Manufacturers can use this information to improve on gown design which will help to prevent future skin exposures to infectious diseases in health care workers. 


\section{DEDICATION}

I wish to dedicate this work to my family and fiancé. Without their support, none of this would have been possible. 


\section{ACKNOWLEDGEMENTS}

I wish to express my sincere gratitude to my advisor and committee chair, Dr. Steve Guffey. You made the process run smoothly and provided me with invaluable resources and guidance. I would also like to thank my committee members, Dr. Selcen Kilinc-Balci and Dr. Xinjian He for your insightful comments and fast responses. I would also like to thank Dr. Jim Harris, Ryan Lebouf, and John Powers for their feedback and support. Last but not least, I would like to thank NIOSH for allowing me to use the laboratory equipment and Dr. Selcen-Kilinc Balci for helping me decide on a topic and also use some of her sample gowns. 


\section{Table of Contents}

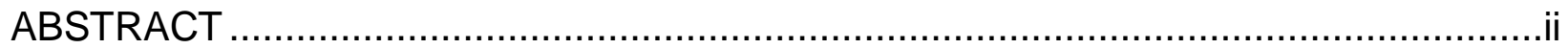

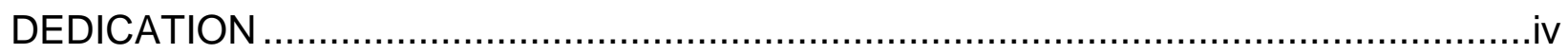

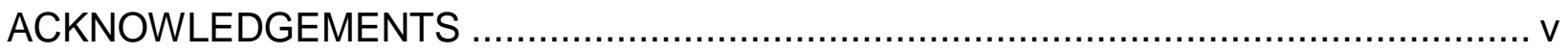

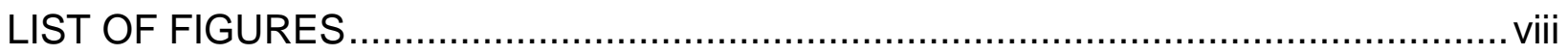

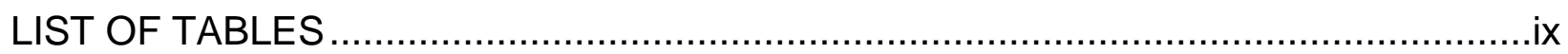

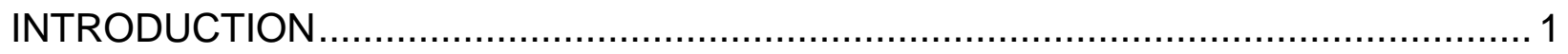

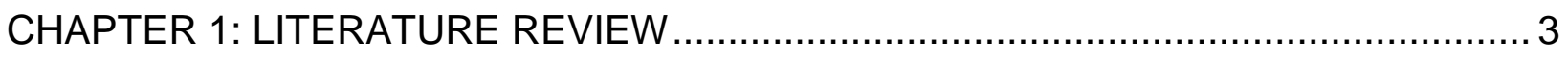

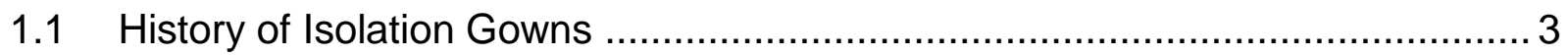

1.2 Occupational Exposure: Health Care Workers ............................................. 4

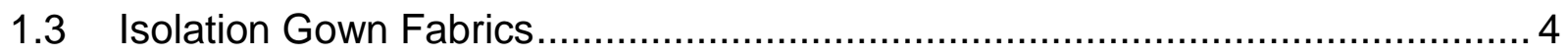

1.4 Current Guidelines, Recommendations, and Requirements .......................... 6

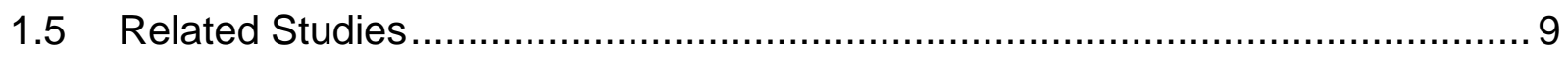

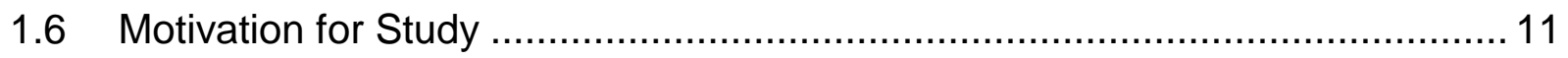

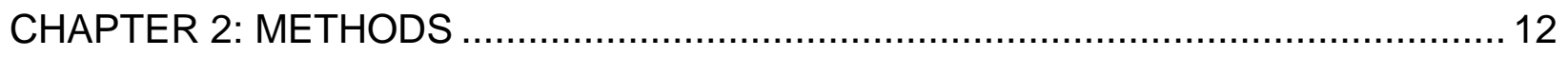

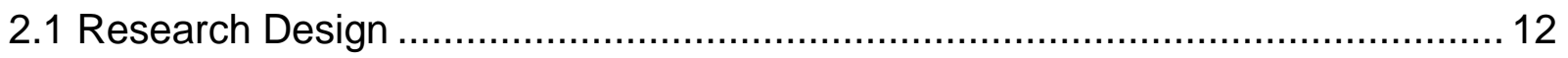

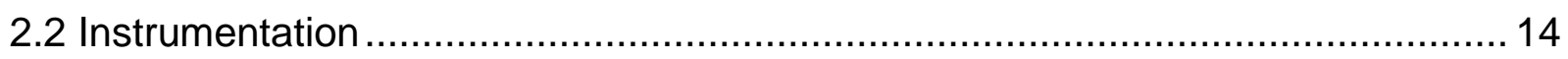

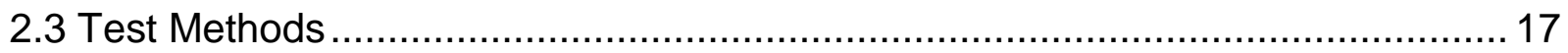

2.4 Data Collection, Entry, Management, and Analysis ......................................... 21

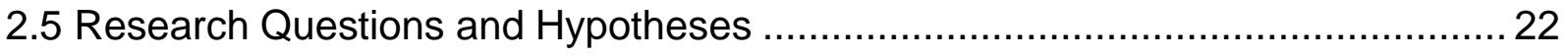

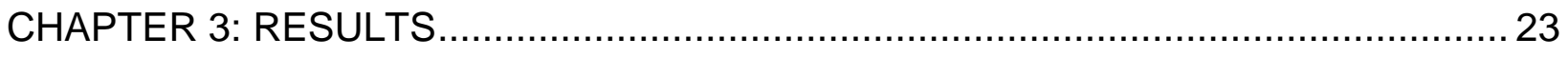

3.1 AATCC 42-2015 Water Resistance: Impact Penetration Results ...................... 23

3.2 AATCC 127-2013 Water Resistance: Hydrostatic Pressure Test Results ........... 27

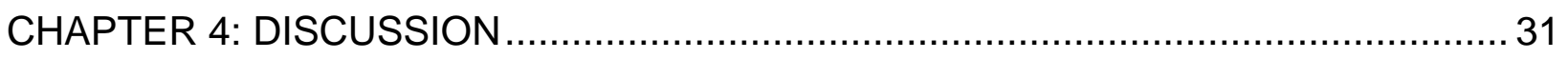

4.1 Cuff barrier performance between ANSI/AAMI PB70 claimed levels of protection 
4.2 Cuffs from claimed Level 1 and 2 liquid barrier performance compared to criteria

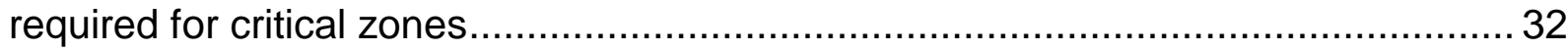

4.3 Cuff barrier performance between number of washings ...................................33

4.4 Cuff barrier performance within ANSI/AAMI PB70 claimed Level 1 protection .... 33

4.5 Cuff barrier performance within ANSI/AAMI PB70 claimed Level 2 protection .... 34

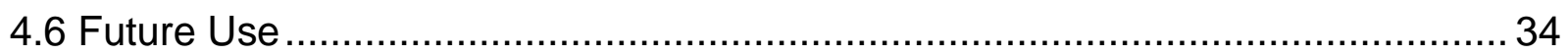

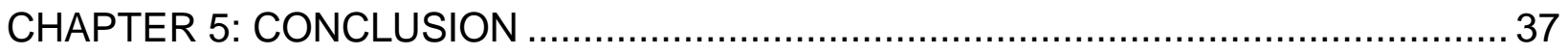

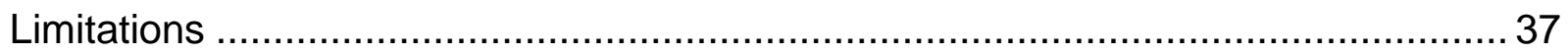

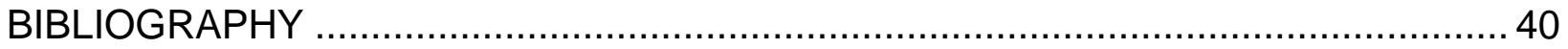




\section{LIST OF FIGURES}

Figure 1. Isolation gown critical zones for exposure (gray areas $A, B$, and $C$ )

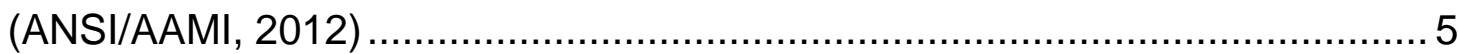

Figure 2. Tester used for Water Impact Penetration testing (AATCC 42-2015) ............ 14

Figure 3. Plum bob hanging $0.6 \mathrm{~m}$ from the spraying head used to modify the spraying to the center of the blotter paper (AATCC 42-2015) ....................................... 15

Figure 4. HydroTester FX 3000-IV used for water pressure resistance testing (AATCC $127-2013) .100 \mathrm{~cm}^{2}$ test head shown ..................................................... 16

Figure 5. Specimen and blotter paper being conditioned at $21^{\circ} \mathrm{C}$ and $65 \%$ relative humidity within the Caron Environmental Chamber.

Figure 6. Example cuff specimen for water impact penetration testing 18

Figure 7 Specimen clamped over a piece of modified blotter paper and held taut with bottom weight

Figure 8. Modified blotter paper clamped underneath cuff specimen

Figure 9. Example specimen for water pressure resistance testing (AATCC 127-2013)

Figure 10. Example of droplet appearance in quick, almost immediate, succession during water pressure resistance testing (AATCC 127-2013)

Figure 11. Comparison of the mean change in weight $(\mathrm{g})$ for sample gowns nested within ANSI/AAMI PB70 levels for the water impact penetration test (AATCC 42-2015) 


\section{LIST OF TABLES}

Table 1. ANSI/AAMI classification requirements for the various levels of protection expected from gowns used in healthcare. All classification levels are for gowns expected to be in direct contact with blood, body fluids, and other potentially infected materials (ANSI/AAMI, 2012; FDA, 2015; NIOSH, 2016). 7

Table 2. Investigator-assigned gown model IDs, ANSI/AAMI PB70 classification claimed by manufacturer for critical zones, and the fabric composition of the critical zones of the isolation gown 13

Table 3. Descriptive statistics for number of washes, ANSI/AAMI liquid barrier classification level, and the interaction between them for the water impact penetration test (AATCC 42-2015) 23

Table 4. LSMeans Student's t-test results for water impact penetration testing (AATCC 42-2015)

Table 5. LSMeans Tukey HSD results for water impact penetration testing (AATCC 422015) for sample gown group comparisons within each ANSI/AAMI PB70 level

Table 6. ANOVA results from JMP (SAS, Cary, NC) for the water impact penetration test (AATCC 42-2015)

Table 7. Number of cuffs from each sample group with change in blotter paper weight

(g) within the requirements for the claimed level of the critical zones. 26

Table 8. Descriptive statistics for number of washes, ANSI/AAMI liquid barrier classification level, and the interaction between them for the water pressure resistance test (AATCC 127-2013).

Table 9. LSMeans Student t-test results for water pressure resistance testing (AATCC 127-2013)

Table 10. LSMeans Tukey HSDresults for water pressure resistance testing (AATCC 127-2013) for sample gown comparisons within each ANSI/AAMI PB70 level 
Table 11. ANOVA results from JMP (SAS, Cary, NC) for the water pressure resistance

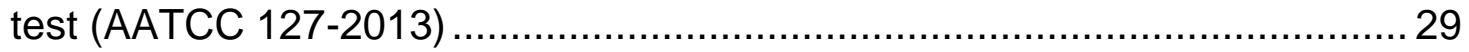




\section{INTRODUCTION}

With the emergence of the Human Immunodeficiency Virus (HIV) in the 1980s, efforts were revived to improve personal protective equipment in the healthcare industry. Over 8 million healthcare workers (HCWs) have the potential to come into contact with infected persons. With threats such as hepatitis B (HBV), HIV, and Ebola virus, isolation gowns that provide adequate protection are desperately needed.

In 2003, the American National Standards Institute (ANSI) and the Association for the Advancement of Medical Instrumentation (AAMI) released a voluntary consensus standard in order to set up a classification system for protective apparel and drapes, including isolation gowns. "Liquid barrier performance and classification of protective apparel and drapes intended for use in healthcare facilities" sets up a clear classification system and standardized test methods for assigning barrier performance classification levels (Level 1-4). The information contained within was originally designed to help end-users determine which gowns are most appropriate for the task at hand. This is currently the only standard for the liquid barrier classification of isolation gowns used in the United States.

At the end of 2015, the FDA set regulations that gowns falling into ANSI/AAMI Levels 3 and 4 barrier performance classifications must be submitted for premarket review (AAMI, 2015; FDA, 2015). Level 3 and 4 gowns provide moderate to high barrier protection respectively and manufacturers must receive FDA clearance before the gowns can be sold. This new regulation does not apply to Level 1 and Level 2 gowns. Few regulations for pre-market design of gowns exist and none of the gowns are examined post-market (FDA, 2015).

Several studies have been performed to examine the barrier effectiveness of isolation gowns (Balci \& D'Alessandro, 2015; Balci et.al., 2015), but none have explored the effectiveness of the cuffs. The performance standard from ANSI/AAMI does not consider cuffs a critical zone for exposure to blood and bodily fluids. Studies have shown the cuffs can be extremely susceptible to contamination with blood and bodily fluid depending on the task performed, duration, type and number of gloves, and 
amount of blood or fluid present (Goldfrank \& Liverman, 2007; Telford \& Quebbeman, 1993). Since there is no legal requirement or a voluntary consensus standard for isolation gown cuffs to meet barrier performance criteria, they are mostly made of materials that provide little to no barrier resistance, such as polyester, cotton, or blends (Kilinc, 2015).

The purpose of this study is to examine the reusable isolation gowns cuffs' resistance to water permeability and compare the findings to the barrier performance requirements for isolation gowns set by ANSI/AAMI. Currently there is very limited data on the water resistance properties of gown cuffs. Examining the cuffs' permeability to water will give an idea as to if the gowns would be susceptible to bodily fluid penetration. However, surface tension of bodily fluids differs from water (Ahmad et al. 1998) so bodily fluids should be considered for use later studies. The significance of the research is that the data could potentially contribute to other data that the National Institute for Occupational Safety and Health (NIOSH) is compiling for design assessment and performance criteria requirements for future standards. These standards will assist manufacturers in creating isolation gowns that provide the best possible protection for HCWs. Protecting HCWs in turn will help prevent the transfer of infectious diseases from contaminated isolation gowns to patients. 


\section{CHAPTER 1: LITERATURE REVIEW}

This chapter contains six parts. First, a review of the history of isolation gowns is presented. Second, information on occupational exposures is presented. Third, a description of common isolation gowns is given. Fourth, current guidelines and recommendations for isolation gowns are presented. Fifth, relevant studies are provided. Lastly, the motivation for the study is given.

\subsection{History of Isolation Gowns}

Isolation gowns have been in use in healthcare since the early 1900s. In 1952, William C. Beck, MD, and T.A. Collete revealed that the muslin gowns that were in use at the time lost all their protective capabilities when they became wet due to the gowns being $100 \%$ cotton and having a low thread count (Belkin, 2000; Belkin, 2002). This revelation wasn't recognized in the healthcare community until the 1970s when the American College of Surgeons (ACS) Committee on the Operating Room Environment (CORE) reached out to the textile community for test methods to be developed that would demonstrate the gown's barrier capabilities. The AAMI considered several test methods for barrier performance of surgical and isolation gowns in order to set up performance standards required by the Food and Drug Administration (FDA) but the committee disbanded in the 1980s without progress after a consensus could not be reached (ANSI/AAMI, 2012; Belkin, 2000).

After the emergence of HIV and HBV in the 1980s, The Centers for Disease Control and Prevention (CDC) made recommendations to reduce exposure to infected blood (Siegel et al., 2007). In 1991, the Occupational Safety and Health Administration (OSHA) issued a federal law which forced employers to provide the appropriate protective equipment to personnel at risk of being exposed to blood in an occupational setting (Ahmad et al., 1998).

HCWs are particularly at risk for exposure to infected bodily fluids, especially surgeons and obstetric staff. Until recently, the failure rates of the most commonly used isolation gowns was unknown (Ahmad et al., 1998). More recently, a NIOSH study 
revealed that seven of the 22 tested disposable models did not meet the ANSI/AAMI PB70 liquid barrier performance standard criteria for protective apparel and drapes (Balci \& D'Alessandro, 2015).

\subsection{Occupational Exposure: Health Care Workers}

HCWs are required to provide care to all patients admitted to the hospital. This puts HCWs at risk to become infected with infectious diseases transmitted via blood or bodily fluids, such as HIV, hepatitis B, hepatitis C, Ebola virus (Gruendemann, 2002; Sepkowitz and Eisenberg, 2005). In general, hospital acquired infections (HAI) are currently the 6th leading cause of death in the United States (Klein et al., 2007), resulting in 100,000 unnecessary annual deaths and over $\$ 5$ billion in associated medical costs (Shannon, 2011).

In response to outbreak of infectious diseases in the HCW population, the CDC and OSHA proposed guidelines for personal protective equipment with the blood borne pathogen standard of 1991 . The standard contributed to reduction of hepatitis $B$ infection rate in HCWs. Currently, there is no way to estimate the exact number of HCW that die annually from occupationally acquired infectious diseases because information on infection rate of many diseases is an educated guess at best. However, it is estimated that 9-42 HCWs per million die annually from HAls (Sepkowitz and Eisenberg, 2005). In total, over 8 million HCWs are in contact with patients, and where there is contact, there is risk for HAls (Bureau of Labor Statistics, 2015).

\subsection{Isolation Gown Fabrics}

Protective gowns are the second most used personal protective equipment (PPE) in healthcare behind gloves (Balci \& D'Alessandro, 2015; Kilinc, 2016). Isolation gowns have varying barrier effectiveness based on the type of material, type of fiber, the permeability of the fabric, and number of uses (Lovitt et al., 1992). Isolation gowns are classified as either "disposable/single-use" or "reusable/multi-use". Disposable (singleuse) isolation gowns are designed to be discarded after a single use and are typically constructed of nonwoven materials alone or in combination with materials that offer 
increased protection from liquid penetration, such as plastic films (Leonas, 2005; Kilinc, 2015).

Reusable (multi-use) gowns are laundered after each use. Reusable isolation gowns are typically made of $100 \%$ cotton, $100 \%$ polyester, or polyester/cotton blends. These fabrics are tightly woven plain weave fabrics that are chemically finished and may be pressed through rollers to enhance the liquid barrier properties. Cuffs in this study were made from polyester with various types of woven structures.

Woven fabrics are made by using two or more sets of yarn interlaced at right angles to each other. Yarns are composed of fibers. Natural fibers such as cotton have a higher absorbency capacity than synthetic fibers like polyester, both of which are commonly found in reusable isolation gowns. The most common woven pattern is a plain weave, which is a simple, regular interlacing pattern. A high thread count indicates that the yarns are closely woven, resulting in a smaller pore size. Regular patterns, however, results in the formation of capillary forces that allow permeability of liquid. If the pattern is irregular, these capillaries become disrupted, reducing permeability (Leonas, 2005; Kilinc, 2015).

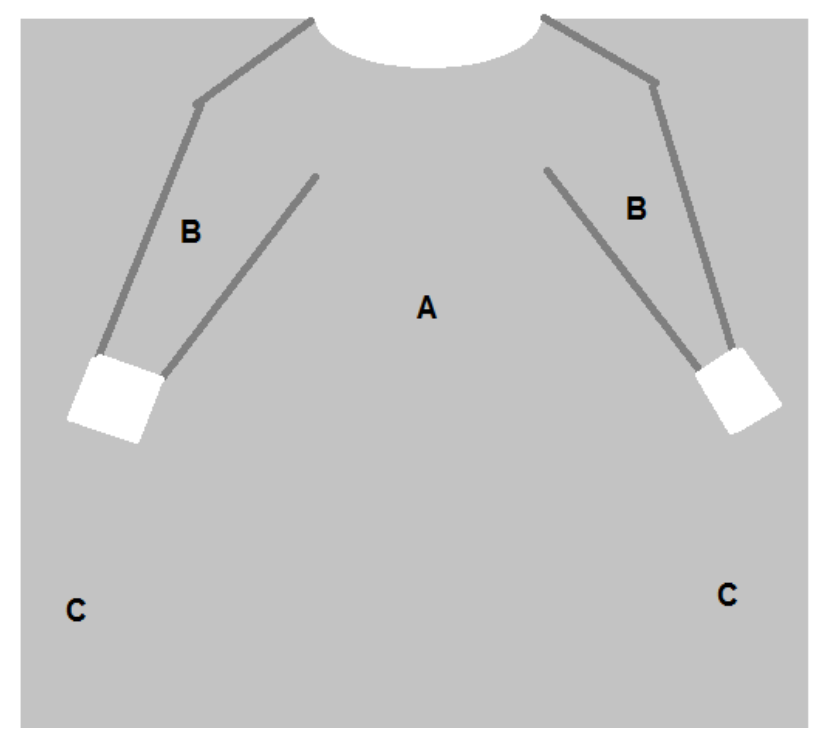

Figure 1. Isolation gown critical zones for exposure (gray areas $A, B$, and C) (ANSI/AAMI, 2012) 
According to the ANSI/AAMI PB70 consensus standard, cuffs are the only part of an isolation gown not considered a critical zone for exposure (Figure 1), which means cuffs do not need to provide the same level of protection as the rest of the gown. Thus, manufacturers do not make cuffs out of the protective material as the body of the gowns. Reusable gown cuffs are generally made from polyester or cotton with a jersey knit structure (Kilinc, 2015). According to Kilinc, FSK (Personal communication, Dec.2016), the knit structure is preferred because it allows for more elasticity and comfort. Adding water resistance material to cuffs increases production costs and reduces comfort. Knitting, which involves interlocking yarns by needles, creates a porous, elastic fabric. Ribbed knits are the most common knit, along with jersey knits (Knit fabrics, n.d.; Knitting, 2016).

\subsection{Current Guidelines, Recommendations, and Requirements}

Current OSHA and CDC guidelines instruct HCWs to always assume that any blood or bodily fluid is contaminated and to wear protective gowns if contact with blood is anticipated (Gruendemann, 2002; OSHA, 2012; Siegel et al., 2007). While OSHA has the responsibility of enforcing PPE use, they take no part in regulation of the market or defining which level of protection the gowns fall under (FDA, 2015). All current consensus standards are voluntary, except for the barrier quality classifications for Level 3 and 4 gowns, which is regulated by the FDA (FDA, 2015). The 2012 ANSI/AAMI PB70 consensus standard is the only available standard for classifying barrier the protection level of isolation gowns (AAMI, 2015). 
Table 1. ANSI/AAMI PB70 classification requirements for the various levels of protection expected from gowns used in healthcare. All classification levels are for gowns expected to be in direct contact with blood, body fluids, and other potentially infected materials (ANSI/AAMI, 2012; FDA, 2015; NIOSH, 2016)

\begin{tabular}{|c|c|c|c|c|}
\hline Level & $\begin{array}{l}\text { Liquid Barrier } \\
\text { Performance } \\
\text { Test; Liquid } \\
\text { Challenge }\end{array}$ & $\begin{array}{c}\text { Minimum } \\
\text { Required } \\
\text { Result }\end{array}$ & $\begin{array}{l}\text { Expected Barrier } \\
\text { Effectiveness }\end{array}$ & Level Description \\
\hline 1 & $\begin{array}{l}\text { AATCC } 42 \text { Impact } \\
\text { Penetration; } \\
\text { Water }\end{array}$ & $\leq 4.50 \mathrm{~g}$ & $\begin{array}{l}\text { Minimal water } \\
\text { resistance (some } \\
\text { resistance to water } \\
\text { spray) }\end{array}$ & $\begin{array}{l}\text { MINIMAL risk situations } \\
\text { Provides a slight barrier } \\
\text { to small amounts of fluic } \\
\text { penetration }\end{array}$ \\
\hline \multirow[t]{2}{*}{2} & $\begin{array}{l}\text { AATCC } 42 \text { Impact } \\
\text { Penetration; }\end{array}$ & $\leq 1.00 \mathrm{~g}$ & \multirow{2}{*}{$\begin{array}{l}\text { Low water resistance } \\
\text { (resistant to water } \\
\text { spray and some } \\
\text { resistance to water } \\
\text { penetration under } \\
\text { constant contact with } \\
\text { increasing pressure) }\end{array}$} & $\begin{array}{l}\text { Used in LOW risk } \\
\text { situations } \\
\text { Provides a barrier to }\end{array}$ \\
\hline & $\begin{array}{l}\text { AATCC } 127 \\
\text { Hydrostatic } \\
\text { Pressure; } \\
\text { Water }\end{array}$ & $\begin{array}{c}\geq 20.00 \mathrm{~cm} \\
\mathrm{H}_{2} \mathrm{O} \\
\text { or } \\
19.61 \mathrm{mbar}\end{array}$ & & $\begin{array}{l}\text { Provides a barrier to } \\
\text { larger amounts of fluid } \\
\text { penetration through } \\
\text { splatter and some fluid } \\
\text { exposure through } \\
\text { soaking }\end{array}$ \\
\hline \multirow[t]{2}{*}{3} & $\begin{array}{l}\text { AATCC } 42 \text { Impact } \\
\text { Penetration; }\end{array}$ & $\leq 1.00 \mathrm{~g}$ & \multirow{2}{*}{$\begin{array}{l}\text { Moderate water } \\
\text { resistance (resistant } \\
\text { to water spray and } \\
\text { some resistance to } \\
\text { water penetration } \\
\text { under constant } \\
\text { contact with } \\
\text { increasing pressure) }\end{array}$} & $\begin{array}{l}\text { Used in MODERATE } \\
\text { risk situations }\end{array}$ \\
\hline & $\begin{array}{l}\text { AATCC } 127 \\
\text { Hydrostatic } \\
\text { Pressure; } \\
\text { Water }\end{array}$ & $\begin{array}{c}\geq 50.00 \mathrm{~cm} \\
\mathrm{H}_{2} \mathrm{O} \\
\text { or } \\
49 \mathrm{mbar}\end{array}$ & & $\begin{array}{l}\text { Provides a barrier to } \\
\text { larger amounts of fluid } \\
\text { penetration through } \\
\text { splatter and more fluid } \\
\text { exposure through } \\
\text { soaking than Level } 2\end{array}$ \\
\hline \multirow[t]{3}{*}{4} & $\begin{array}{l}\text { ASTM F1670 } \\
\text { Synthetic Blood } \\
\text { Penetration Test } \\
\text { (for surgical } \\
\text { drapes); }\end{array}$ & $\begin{array}{l}\text { no } \\
\text { penetration } \\
\text { at } 2 \mathrm{psi} \\
(13.80 \mathrm{kPa})\end{array}$ & \multirow[t]{3}{*}{$\begin{array}{l}\text { Blood and viral } \\
\text { penetration } \\
\text { resistance (2 psi) }\end{array}$} & $\begin{array}{l}\text { Used in HIGH risk } \\
\text { situations } \\
\text { Prevents all fluid } \\
\text { penetration for up to } 1 \\
\text { hour }\end{array}$ \\
\hline & Surrogate Blood & & & \multirow{2}{*}{$\begin{array}{l}\text { May prevent VIRUS } \\
\text { penetration for up to } 1 \\
\text { hour }\end{array}$} \\
\hline & $\begin{array}{l}\text { ASTM F1671 Viral } \\
\text { Penetration Test } \\
\text { (for surgical and } \\
\text { isolation gowns); } \\
\text { Bacteriophage } \\
\text { Phi-X174 }\end{array}$ & $\begin{array}{c}\text { no } \\
\text { penetration } \\
\text { at } 2 \mathrm{psi} \\
(13.80 \mathrm{kPa})\end{array}$ & & \\
\hline
\end{tabular}


ANSI/AAMI PB70 classifications for the barrier performance requirements of isolation gowns are shown in Table 1. Table 1 lists the various liquid barrier challenge tests required for each level of protection. Levels of protection are ranked as minimal, low, moderate or high barrier protection (see Table 1 for definitions). Levels 1 and 2 are considered to be for minimal and low barrier protection, respectively. Levels 3 and 4 are to be used for moderate or high barrier protection respectively (FDA, 2012). The classification information provided in the table is only used to assist manufacturers in labeling their pre-market products. The FDA requires that gowns meeting AAMI Level 3 and 4 classification must pass the required performance tests in addition to other requirements.

Only gowns claimed to be Level 1 and 2 were used in this study. Currently, OSHA and CDC are the two agencies that provide recommendations for choosing gowns based on task type and duration (OSHA, 2012; NIOSH, 2016). The end user is responsible for determining the appropriate gown based on known exposure risks and the specific procedures and techniques involved (ANSI/AAMI, 2012).

The ANSI/AAMI consensus standard includes two water permeability tests from the American Association of Textile Chemists and Colorists (AATCC) to evaluate barrier effectiveness of isolation gowns (ANSI/AAMI, 2015). The standard tests are as follows:

- AATCC 42-2015 Water Resistance: Impact Penetration Test: measures the change in blotter paper weight to detect water penetration through fabric. A lower number represents less water penetration through fabric (AATCC 42-2015, 2015).

- AATCC 127-2013 Water Resistance: Hydrostatic Pressure Test: measures a fabrics resistance to water penetration under increasing hydrostatic pressure $(60 \mathrm{mbar} / \mathrm{min})$. A higher number indicates a higher resistance to penetration (AATCC 127-2013, 2013).

These tests are used to confirm the level of protection claimed by the manufacturer. The FDA (2015) requires that reusable gowns be tested both on preshipment gowns (i.e., new gowns) and on gowns laundered to the maximum number of recommended cycles. All maximum laundered gowns in this study were washed 75 
times except for sample group $\mathrm{H}$, which was washed 100 times based on the recommended laundering cycle information provided by the manufacturers.

\subsection{Related Studies}

Granzow et al. (1998) tested the front panels of two, $100 \%$ cotton reusable isolation gowns. One of the gowns was new and the other was washed an unknown number of times. The investigators measured the migration of blood, either normal or infected with Methicillin-resistant staphylococcus aureus (MRSA), through the gown according to the Level 4 gown requirements in ANSI/AAMI PB70. Washed reusable gowns were found to be less protective than their new unwashed versions.

Zachary et al. (2001) measured contamination rate of gloves, gowns, and stethoscopes during routine examination of patients with vancomycin-resistant enterococci (VRE). After patient examination, gloves, gowns, and stethoscopes were tested for VRE contamination. Gloves in $63 \%$ cases were contaminated with VRE. Medical examiner gowns were contaminated in 37\% cases, and stethoscope diaphragms were contaminated in $31 \%$ of cases. Contamination of medical personnel PPE with VRE was found to be common during routine physical exams. It was not noted if gloves covered the cuffs of the gowns.

Various studies disagree if isolation gowns reduce the risk of HAls (Balci, 2016). Donowitz, (1986), Birenbaum et al., (1990), and Renaud, (1983) found no difference in the rates of HAls with HCW isolation gown use. Klein et al., (2007) and Agbayani et al. (1981) found a decrease in HAls with HCW isolation gown use.

Ahmad et al. (1998) found that of 1022 isolation gowns worn by HCW, 44\% had evidence of blood penetration. Compliance with proper donning and doffing was a concern. Only $25.2 \%$ of medical personnel wearing PPE were compliant. Even when proper procedures were followed, there was a high failure rate $(14.8 \%)$ of isolation gowns considered to be impenetrable. Most importantly, the authors noted that even a single droplet of blood can contain thousands of blood-borne pathogens and is enough to cause transmission of infectious disease. 
Telford and Quebbeman (1993), Smith et al. (1991), and Granzow et al. (1998) have shown that reusable gowns become less effective with increasing number of washes. Slater (1998) found that disposable gowns prevent more penetration than reusable gowns, but at the cost of comfort and breathability that the reusable gowns provide.

Rutala and Weber (2001) examined the economic and environmental impact of disposable and reusable gowns. They found that disposable gowns create more physical waste but reusable gowns consume more water and create more water pollution. Both gown types were found to release air emissions that contribute to the formation of greenhouse gasses and acid rain. Both forms of pollution are viewed as equally damaging to the environment. From an economic standpoint, Rutala and Weber compared direct costs, drape set-up and changing costs, laundering and reprocessing costs, storage and inventory costs, and disposal costs. The total cost and cost-per-use both came out to roughly the same amounts for disposable and reusable gowns. They mentioned it was important to examine the actual life span of reusable gowns. These gowns claim to be viable for up to 100 laundering cycles by the manufacturer. However, physical damage and decreased efficiency with increasing number of washings may reduce the viable life span by $50 \%$.

Balci, F.S.K., Nwoko, J., and Hillam, T. (2015) assessed 22 types of disposable isolation gowns using two of the liquid barrier performance tests (water impact penetration and hydrostatic pressure resistance) and one viral penetration resistance test (ASTM F1671) within the ANSI/AAMI PB70 consensus standard. They found that 9 of the 22 new disposable isolation gowns did not meet the ANSI/AAMI PB70 minimum performance criteria for barrier protection level claimed by the manufacturers.

Depending on the amount of blood or bodily fluids involved with certain tasks as well as the type and number of gloves used, cuffs may not provide adequate protection from contamination and penetration. HCWs may not experience adequate protection. Goldfrank and Liverman (2007) found that the areas of the gowns most vulnerable to strike-through (i.e. migration of fluid from one side of fabric to the other) were the cuffs, forearms, thigh, chest, and abdomen areas. The gown/glove interface is known to have 
leakage and contamination issues (Goldfrank \& Liverman, 2007; Telford \& Quebbeman, 1993), but the ANSI/AAMI PB70 standard doesn't address the interface because too

many factors other than the gown itself can affect the interface (ANSI/AAMI, 2012). It is recommended that gloves be pulled over cuffs in all cases, but user compliance is a concern (Goldfrank \& Liverman, 2007). Even more concerning is that gown cuffs have been found to fail even when users are compliant with donning and doffing procedures for PPE (Ahmad et al., 1998).

\subsection{Motivation for Study}

HCWs are often exposed to bodily fluids that may or may not contain infectious diseases. A single drop of blood is enough to transmit infectious disease (Ahmad et al., 1998). Balci (2016), Kilinc et al. (2015), Smith et al. (1991), and Telford and Quebbeman (1993) identified isolation gowns on the market that do not provide the claimed level of protection. The protection rate for isolation gowns is unknown.

In particular, no studies have explored the liquid barrier performance of isolation gown cuffs. The cuff area is a concern because it is the only area of isolation gowns not considered a critical zone for exposure by ANSI/AAMI PB70. Also, gown cuffs have been found to fail even when users are compliant with donning and doffing procedures for PPE (Ahmad et al., 1998). Therefore, it is the subject of this study to examine the liquid barrier performance of cuffs and compare findings to the classification requirements found in ANSI/AAMI PB70. 


\section{CHAPTER 2: METHODS}

This chapter contains five parts. First, the research study design is presented. Second, information on the instrumentation used is provided. Third, the test methods are given. Fourth, information on data handling and analysis are presented. Lastly, the research questions and hypotheses are presented.

\subsection{Research Design}

$\mathrm{NIOSH}$ procured reusable isolation gowns, either ANSI/AAMI PB70 classification Level 1 or Level 2, from the open market for use in this study regarding barrier effectiveness. Cuffs were taken from these samples, with the researcher being blinded to the manufacturer names. 
Table 2. Investigator-assigned gown model IDs, ANSI/AAMI PB70 classification claimed by manufacturer for critical zones, and the fabric composition of the critical zones of the isolation gown

\begin{tabular}{|c|c|c|c|c|}
\hline $\begin{array}{l}\text { Sample } \\
\text { Gown } \\
\text { ID }\end{array}$ & $\begin{array}{l}\text { AAMI } \\
\text { Level } \\
\text { Claimed } \\
\text { for } \\
\text { Critical } \\
\text { Zones } \\
\end{array}$ & $\begin{array}{c}\text { Maximum } \\
\text { Number of } \\
\text { Launderings } \\
\text { Recommended } \\
\text { by the } \\
\text { Manufacturer }\end{array}$ & $\begin{array}{l}\text { Critical Zone } \\
\text { Woven Fabric } \\
\text { Composition }\end{array}$ & $\begin{array}{l}\text { Cuff Fiber } \\
\text { Composition }\end{array}$ \\
\hline A & 2 & 75 & $100 \%$ Polyester & $100 \%$ Polyester \\
\hline B & 1 & 75 & $100 \%$ Polyester & $\begin{array}{l}100 \% \text { Polyester } \\
\text { Jersey }\end{array}$ \\
\hline C & 2 & 75 & $\begin{array}{l}99 \% / 1 \% \\
\text { Polyester/Carbon } \\
\text { Fiber }\end{array}$ & $100 \%$ Polyester \\
\hline D & 2 & 75 & $\begin{array}{l}99 \% / 1 \% \\
\text { Polyester/Carbon } \\
\text { Fiber }\end{array}$ & $100 \%$ Polyester \\
\hline $\mathrm{F}$ & 1 & 75 & $\begin{array}{l}99 \% / 1 \% \text { Polyester/ } \\
\text { Carbon Fiber }\end{array}$ & $\begin{array}{l}100 \% \text { Polyester } \\
\text { Jersey }\end{array}$ \\
\hline $\mathrm{H}$ & 1 & 100 & $\begin{array}{l}55 \% / 45 \% \\
\text { Cotton/Polyester }\end{array}$ & $\mathrm{N} / \mathrm{A}$ \\
\hline
\end{tabular}

Sample gown groups were assigned a label (A, B, C, D, F, or H) (Table 2). Gowns were washed and dried once or to the maximum laundering cycles recommended by the manufacturers. All gown model groups washed multiple times were washed for 75 cycles, except for model $\mathrm{H}$ which was washed 100 times based on the manufacturers recommendations.

Thirty-two cuff specimens were taken from each of the 6 gown models. Sixteen specimens were taken from the washed once gowns and sixteen from the maximum laundered gowns. A total of 192 ( 16 specimen $\times 6$ sample gowns $\times 2$ types of laundering) cuffs were tested per standard for a grand total of 384 specimen. Both test methods were modified to accommodate the smaller sample surface area. See section 
"2.2 Instrumentation" and "2.3 Test Methods" for modifications. Cuffs were conditioned according to the "Standard Practice for Conditioning and Testing Textiles" (ASTM D1776/D1776M) as stated in both test methods. All specimen were tested at room temperature and humidity.

Results were statistically analyzed in JMP (SAS, Cary, NC) for the ANSI/AAMI PB70 levels of protection (Levels 1 and 2), and also for number of washings (one time versus maximum laundered). Interactions between levels and number of washings were also examined. The results of both tests were compared to the requirements listed in ANSI/AAMI PB70:2012 for the critical zones of isolation gowns.

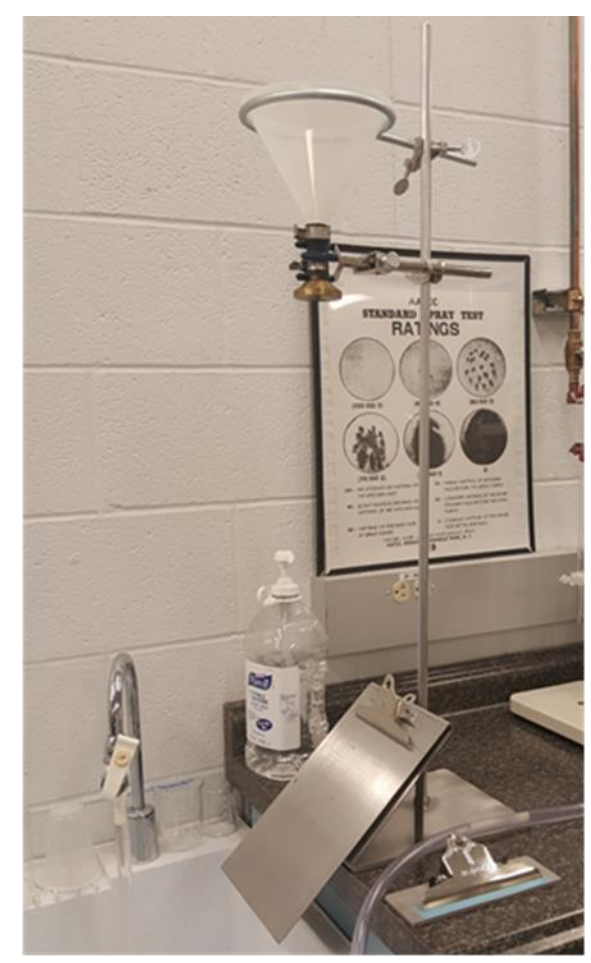

Figure 2. Tester used for Water Impact Penetration testing (AATCC 42-2015)

\subsection{Instrumentation}

For water impact penetration testing (AATCC 42-2015), an impact penetration Type II tester (Figure 2) was used, consisting of a funnel with interior baffles on a ring stand $0.6 \mathrm{~m}$ above a clip board angled 45 -degrees to the horizontal. The height of the funnel and spraying head was maintained to the required distance of $0.6 \mathrm{~m}$. 


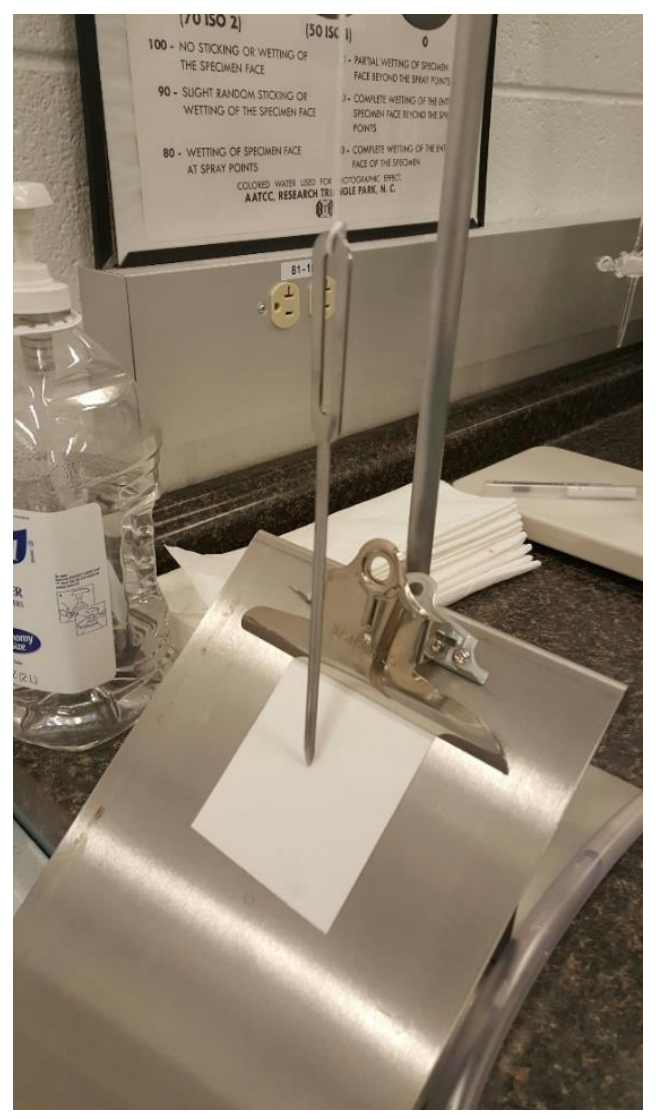

Figure 3. Plum bob hanging $0.6 \mathrm{~m}$ from the spraying head used to modify the spraying to the center of the blotter paper (AATCC 42-2015)

A plum bob was used to modify and align the spraying head (Figure 3) so that water sprayed half way down on the center of the blotter paper (approximately $4.5 \mathrm{~cm}$ from the bottom of the clamp at the top of the clip board). Also, a $250 \mathrm{ml}$ beaker instead of a $500 \mathrm{~mL}$ beaker and a scale precise to the nearest $0.01 \mathrm{~g}$ were used. 


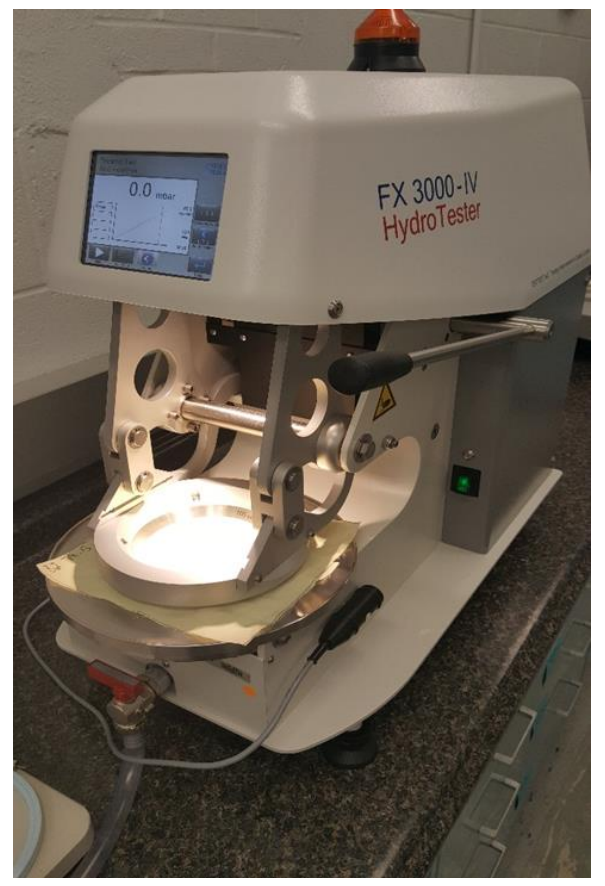

Figure 4. HydroTester FX 3000-IV used for water pressure resistance testing (AATCC 1272013). $100 \mathrm{~cm}^{2}$ test head shown

For hydrostatic pressure water resistance testing (AATCC 127-2013), a HydroTester (Figure 4) meeting Option 2 for hydrostatic head tester requirements of the standard was used. The hydrostatic tester functions by clamping a specimen between two rings directly on touching the top of a reservoir of water. The clamping surface was modified from the required $100 \mathrm{~cm}^{2}$ clamping surface area to that of $26 \mathrm{~cm}^{2}$ using the smaller testing head provided by the manufacturer. The HydroTester used has a digital display from which test type can be set. In this case dynamic testing was used, and the rising pressure rate was set to the required $60 \mathrm{mbar} / \mathrm{min}$. This same screen also displays the water penetration pressures triggered by the operator pressing a button. 


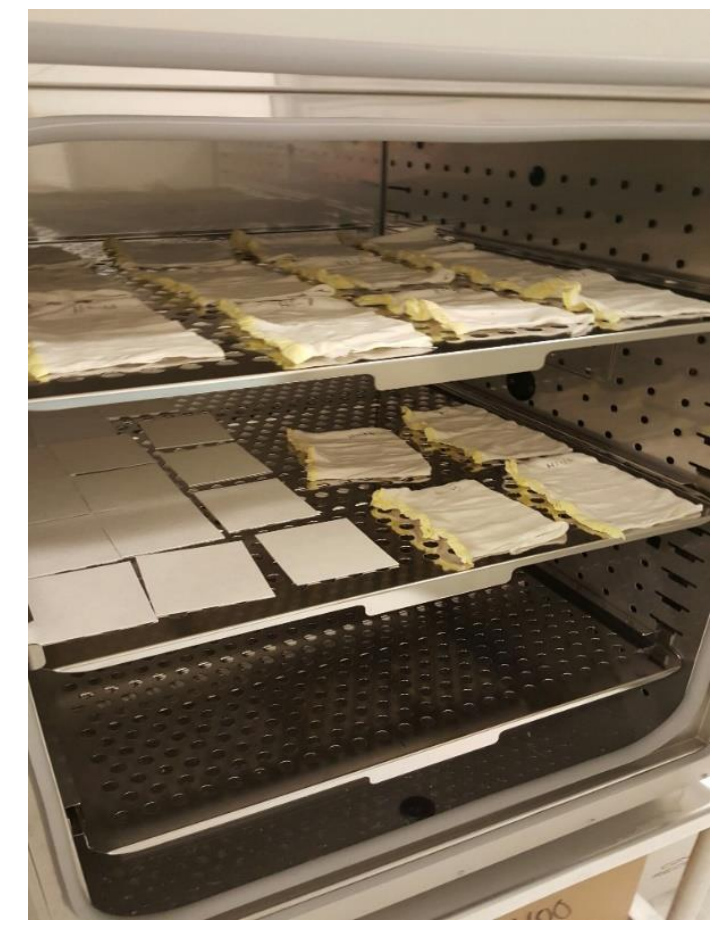

Figure 5. Specimen and blotter paper being conditioned at $21^{\circ} \mathrm{C}$ and $65 \%$ relative humidity within the Caron Environmental Chamber

\subsection{Test Methods}

For both test methods, specimen were conditioned according to the "Standard Practice for Conditioning and Testing Textiles" (ASTM D1776/D1776M) as specified in AATCC 42-2015 and AATCC 127-2013 test methods. All specimen and blotting paper were placed in a conditioning chamber (Caron 6010 Series Environmental Chamber, Marietta, $\mathrm{OH}$; Figure 5) set to $21^{\circ} \mathrm{C}$ and $65 \%$ relative humidity for at least four hours prior to testing. According to Balci, F.S.K. (Personal communication, November 29, 2016), fabrics are conditioned at standard atmosphere to avoid the unwanted effects temperature and humidity can have on the properties of fabrics. For example, fabrics such as cotton more readily absorb water so conditioning all fabrics at standard atmosphere allows different fabric types to be compared when using the same test methods. 


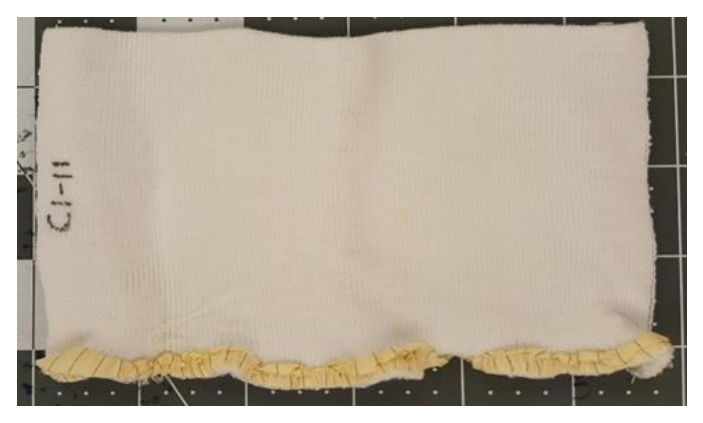

Figure 6. Example cuff specimen for water impact penetration testing

For the water impact penetration test (AATCC 42-2015), the cuff specimen were cut just above the seam (Figure 6), leaving the seam in-tact in order to keep the material together. The specimen was layered over a piece of pre-weighed modified blotting paper and clamped onto the top of a clipboard angled at $45^{\circ}$ to the horizontal under the funnel spraying head (Figure 7 and 8 ). 


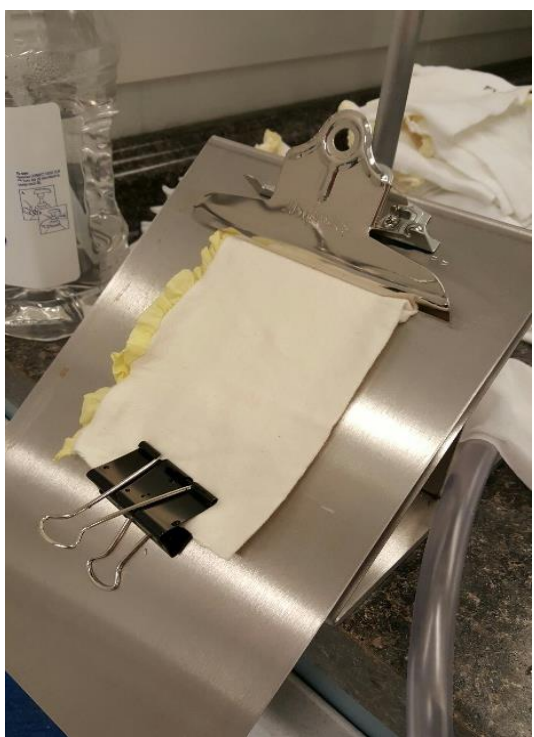

Figure 7 Specimen clamped over a piece of modified blotter paper and held taut with bottom weight

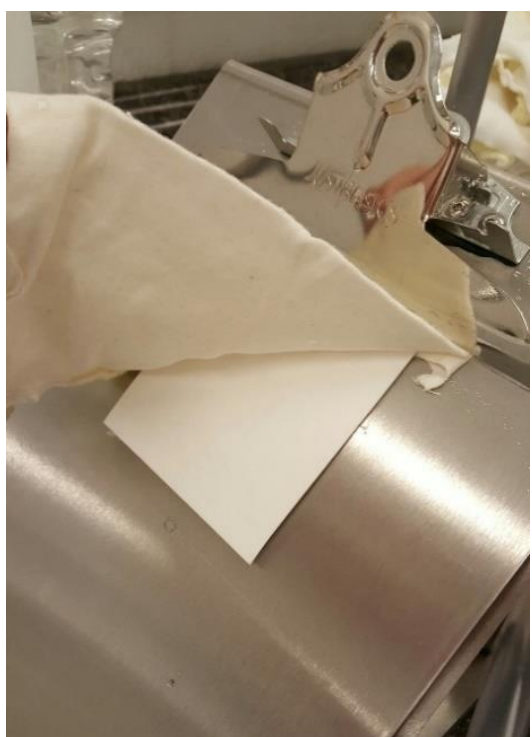

Figure 8. Modified blotter paper clamped underneath cuff specimen

Blotting paper was cut down to a smaller size based on the original specimen size to blotter paper size ratio using the average cuff size. The bottom of the sample was clamped with an additional clamp (Figure 7) that was allowed to hang down to hold the sample taut. One hundred fifteen milliliters of distilled water, modified from the original $500 \mathrm{~mL}$ using a ratio of original sample size to $500 \mathrm{~mL}$ distilled water, was poured into the funnel using a $250 \mathrm{~mL}$ beaker and allowed to spray onto the angled cuff surface. Once the water stopped spraying, the specimen was quickly removed from the clip board and the blotting paper was re-weighed. The change in weight in grams was recorded. Water was to be regulated at $21 \pm 2^{\circ} \mathrm{C}$, but the laboratory did not have the capabilities to do so. Water temperature was recorded with the data in the lab notebook. 


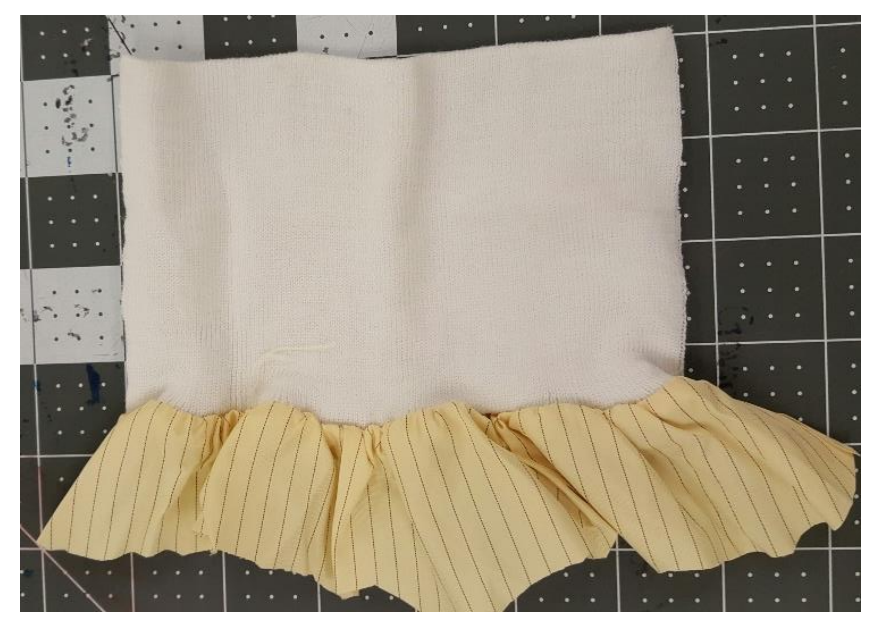

Figure 9. Example specimen for water pressure resistance testing (AATCC 127-2013)

For the water pressure resistance test (AATCC 127-2013), samples were cut to a minimum size of the clamping surface $\left(26 \mathrm{~cm}^{2}\right)$, which in this case was the entire cuff (Figure 9). The surface of the fabric to be tested, the outside of the sleeve and cuff, was placed face down onto the water and clamped into place. Water in the reservoir of the HydroTester was to be regulated at $21 \pm 2^{\circ} \mathrm{C}$, but the laboratory did not have the capabilities to do so. Water temperature was recorded with the data in the lab notebook. The dynamic test option on the HydroTester was selected with a pressure gradient of $60 \mathrm{mbar} / \mathrm{min}$. 


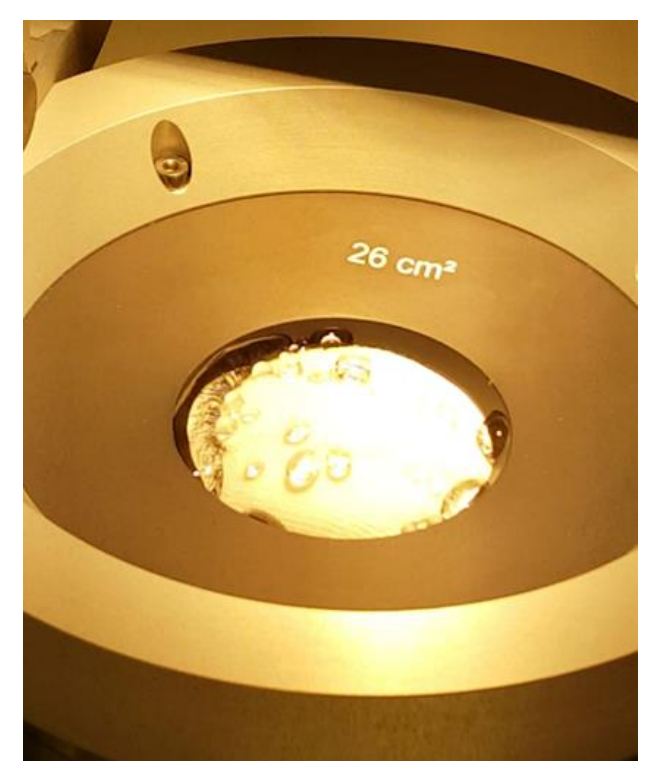

Figure 10. Example of droplet appearance in quick, almost immediate, succession during water pressure resistance testing (AATCC 127-2013)

When the test was started, water pressure under the fabric rose and the operator pressed a trigger button for the first three droplets that penetrated the cuff, disregarding any droplets that appeared within $3 \mathrm{~mm}$ of the clamp ring as per the standard methods. The pressure (mbar) of the first three unique locations to penetrate the cuffs were recorded in the laboratory notebook. The third water droplet penetration location pressure (mbar) was used for statistical analysis and comparison to the ANSI/AAMI PB70 level classification criteria (Figure 10).

\subsection{Data Collection, Entry, Management, and Analysis}

Data was recorded from the scale and from the HydroTester screen directly into a laboratory notebook. Data was then transferred into Excel${ }^{\circledR}$. The data analysis for this paper was generated using SAS software, specifically JMP (SAS, Cary, NC). Data obtained was also compared to the guidelines for liquid barrier classification provided by ANSI/AAMI PB70:2012 consensus standard (Table 1) for critical zones. A factorial analysis of variance (ANOVA) was used for statistical analysis at $p<0.05$ for each of the hypotheses listed below (Section 2.5 Research Questions and Hypotheses). LSMeans 
Student's t-tests were used to compare the two levels within each independent variable, number of washings and ANSI/AAMI PB70 level. The LSMeans Tukey HSD was used to analyze the differences between sample groups nested within each ANSI/AAMI PB70 level.

\subsection{Research Questions and Hypotheses}

The research questions were:

- Do the cuffs meet the liquid barrier performance criteria expected for the ANSI/AAMI level claimed by the manufacturer for the rest of the gown?

- Does washing the gown cuffs to the maximum recommended number of cycles, reduce the liquid barrier performance?

- Do sample gowns within each ANSI/AAMI classification level provide the same liquid barrier performance?

\section{The main hypotheses were:}

- Cuffs from gowns within the ANSI/AAMI PB70 Level 2 classification will have significantly higher liquid barrier performance than the cuffs from gowns in the Level 1 classification.

- Cuffs from sample gowns claimed to be Level 1 will not meet the liquid barrier performance criteria required for critical zones.

- Cuffs from sample gowns claimed to be Level 2 will not meet the liquid barrier performance criteria required for critical zones.

- Gown cuffs washed to the maximum recommended number of laundering cycles will have decreased liquid barrier performance compared to cuffs only washed once

- Sample gown cuffs $B, F$, and $H$ will have significantly different barrier performance within ANSI/AAMI PB70 Level 1.

- Sample gown cuffs A, C, and D will have significantly different barrier performance within ANSI/AAMI PB70 Level 2. 


\section{CHAPTER 3: RESULTS}

This section presents the results from the water resistance impact penetration test and the hydrostatic pressure resistance test.

\subsection{AATCC 42-2015 Water Resistance: Impact Penetration Results}

An ANOVA and post hoc tests were performed on the change in blotter paper weight $(\mathrm{g})$ data from the water impact penetration test.

Table 3. Descriptive statistics for number of washes, ANSI/AAMI liquid barrier classification level, and the interaction between them for the water impact penetration test (AATCC 42-2015)

\begin{tabular}{lccc}
\hline \multicolumn{1}{c}{ Specimen Source } & n & $\begin{array}{c}\text { Mean Change in } \\
\text { Blotter Paper } \\
\text { Weight (g) }\end{array}$ & SD \\
\hline Cuffs Washed 1 Time & 96 & 2.49 & 2.84 \\
Cuffs Washed Multiple Times & 96 & 5.70 & 1.37 \\
Cuffs from Level 1 Gowns & 96 & 5.42 & 2.00 \\
Cuffs from Level 2 Gowns & 96 & 2.77 & 2.76 \\
Cuffs from Level 1 Gowns Washed 1 Time & 48 & 4.71 & 2.42 \\
Cuffs from Level 1 Gowns Maximum Laundered & 48 & 6.13 & 1.08 \\
Cuffs from Level 2 Gowns Washed 1 Time & 48 & 0.27 & 0.61 \\
Cuffs from Level 2 Gowns Maximum Laundered & 48 & 5.27 & 1.50 \\
\hline
\end{tabular}

Table 3 shows the descriptive statistics for the water impact penetration test. The mean change in blotter paper weight $(g)$ for cuffs washed multiple times $(M=5.70)$ was more than double than the mean for cuffs washed 1 time $(M=2.49)$. Cuffs from Level 1 gowns had a mean change in blotter paper weight $(g)(M=5.42)$ that was also more than double the mean for cuffs from Level 2 gowns ( $M=2.77)$. Level 1 gown cuffs ( $M=6.13)$ and Level 2 gown cuffs $(M=5.27)$ laundered to the maximum cycles allowed 
more water to penetrate the fabric than Level 1 gown cuffs $(M=4.71)$ and Level 2 gown cuffs $(M=0.27)$ only washed once.

Table 4. LSMeans Student's t-test results for water impact penetration testing (AATCC 42-2015)

\begin{tabular}{lc}
\hline Comparison & Prob $>|t|$ \\
\hline Level 1 vs Level 2 & $<0.0001$ \\
Washed Once vs Max Laundered & $<0.0001$ \\
\hline
\end{tabular}

The LSMeans Student's t-test shows a significant difference between number of washings $(p<0.0001)$ with gowns washed multiple times $(M=5.70)$ having a higher mean change in blotter paper weight $(\mathrm{g})$ than gowns washed once $(M=2.49)$. There was also a significant difference $(p<0.0001)$ between cuffs from gowns claimed as Level 1 and Level 2, with Level 1 gowns having a higher mean change in blotter paper weight ( $M=5.42)$ versus Level $2(M=2.77)$.

Table 5. LSMeans Tukey HSD results for water impact penetration testing (AATCC 42-2015) for sample gown group comparisons within each ANSI/AAMI PB70 level

\begin{tabular}{lc}
\hline \multicolumn{1}{c}{ Comparison } & p-Value \\
\hline Sample Gown B vs Sample Gown F (within Level 1) & 0.71 \\
Sample Gown B vs Sample Gown H (within Level 1) & $<0.0001$ \\
Sample Gown F vs Sample Gown H (within Level 1) & $<0.0001$ \\
Sample Gown A vs Sample Gown C (within Level 2) & 0.76 \\
Sample Gown A vs Sample Gown D (within Level 2) & 0.99 \\
Sample Gown C vs Sample Gown D (within Level 2) & 0.50 \\
\hline
\end{tabular}

The LSMeans Tukey HSD test (Table 5) revealed that within the Level 1 claimed classification, cuffs from sample gowns B and F performed similar ( $p>0.05)$. Both were 
different from cuffs from sample gown $\mathrm{H}(\mathrm{p}<0.001)$. This may be due to cuffs $\mathrm{H}$ being washed 25 more times than sample gowns $B$ and $F$. All 3 cuffs from sample gowns $A$, $C$, and D within the Level 2 claimed classification performed similar (no significant difference, $p>0.05$ ).

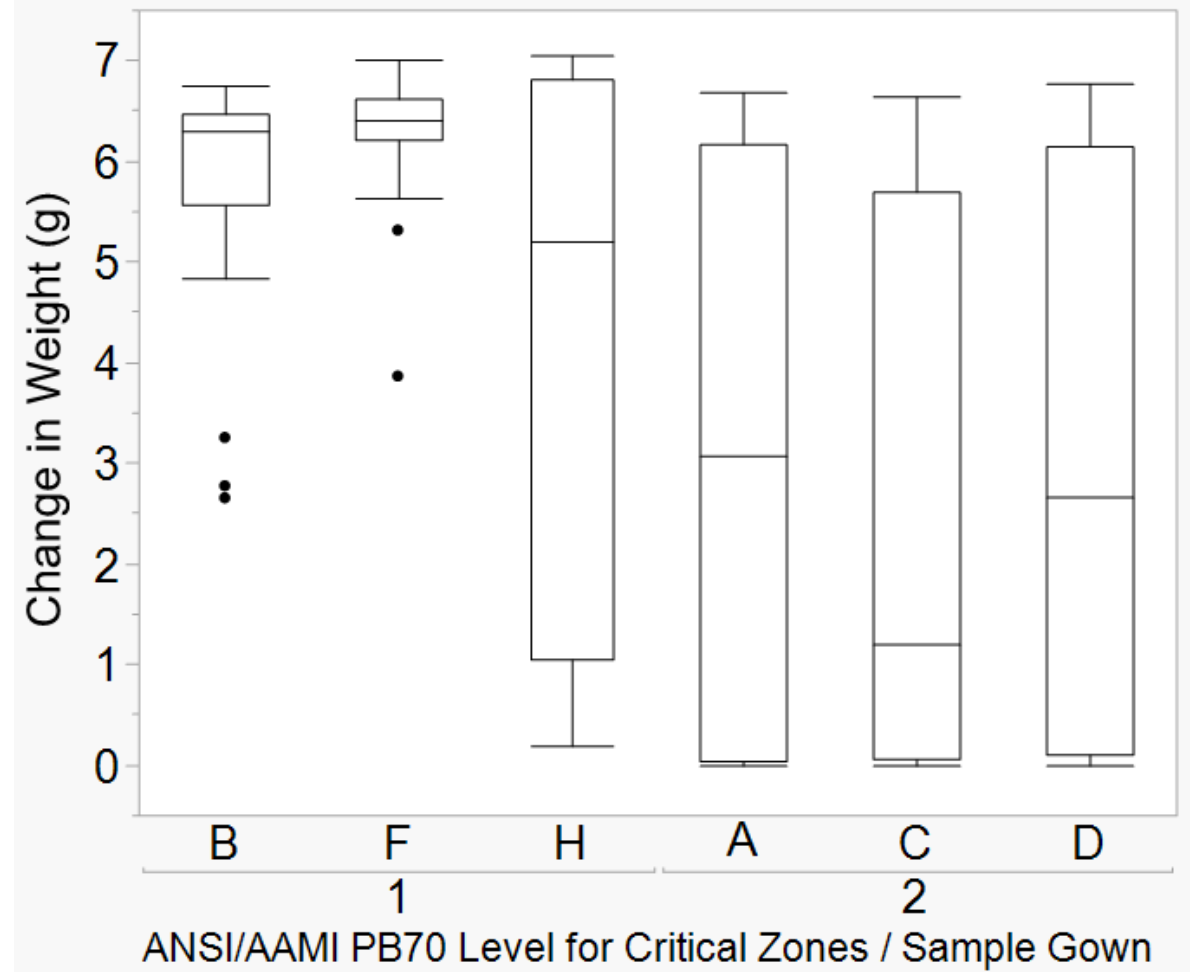

Figure 11. Comparison of the mean change in weight $(g)$ for sample gowns nested within ANSI/AAMI PB70 levels for the water impact penetration test (AATCC 42-2015)

Figure 11 shows compares the mean changes in blotter paper weight $(\mathrm{g})$ for the 6 sample gown cuffs. Sample group B and F cuffs performed similarly, with both allowing more water through the fabric onto the blotter paper. As mentioned before, sample gown $\mathrm{H}$ cuffs had been laundered an additional 25 times compared to all other sample gown groups, thus the mean change in blotter paper weight $(\mathrm{g})$ doesn't resemble either Level 1 or Level 2 gown cuffs. All three gowns (A, C, and D) within Level 2 performed similarly ( $p>0.05$ ). 
Table 6. ANOVA results from JMP (SAS, Cary, NC) for the water impact penetration test (AATCC 42-2015)

\begin{tabular}{lcccc}
\hline \multicolumn{1}{c}{ Source } & $\begin{array}{c}\text { Degrees of } \\
\text { Freedom }\end{array}$ & $\begin{array}{c}\text { Sum of } \\
\text { Squares }\end{array}$ & F Ratio & Prob $>$ F \\
\hline AAMI PB70 Level Claimed & 1 & 337.40 & 170.67 & $<.0001^{*}$ \\
Number of Times Washed & 1 & 495.50 & 250.64 & $<.0001^{*}$ \\
$\begin{array}{l}\text { Sample Gowns nested within AAMI } \\
\text { PB70 Claimed Levels }\end{array}$ & 4 & 90.35 & 11.43 & $<.0001^{*}$ \\
$\begin{array}{l}\text { AAMI PB70 Claimed Levels } \\
\text { crossed with Number of Times }\end{array}$ & 1 & 154.51 & 78.16 & $<.0001^{*}$ \\
Washed & & & & \\
\hline
\end{tabular}

A factorial ANOVA (Table 6) was conducted to compare number of washings and the AAMI PB70 claimed level on the cuffs' barrier performance against water impact penetration. The interaction effect of both number of washings and AAMI PB70 level was also compared. All independent variables and combinations of variables were significant at the $5 \%$ level. The findings of this test are likely not due to chance.

Table 7. Number of cuffs from each sample group with change in blotter paper weight $(g)$ within the requirements for the claimed level of the critical zones

\begin{tabular}{ccccc}
\hline $\begin{array}{c}\text { Sample } \\
\text { Group }\end{array}$ & $\begin{array}{c}\text { Number of } \\
\text { Times } \\
\text { Washed }\end{array}$ & $\mathbf{n}$ & Level & $\begin{array}{c}\text { Number of Specimen } \\
\text { passing ANSI/AAMI } \\
\text { PB70 Criteria }\end{array}$ \\
\hline B & 75 & 16 & 1 & 3 \\
F & 75 & 16 & 1 & 1 \\
H & 1 & 16 & 1 & 16 \\
A & 1 & 16 & 2 & 14 \\
C & 1 & 16 & 2 & 16 \\
D & 1 & 16 & 2 & 13 \\
\hline
\end{tabular}


Critical zones of gowns claimed as Level 1 can only have a change in blotter paper weight $\leq 4.5 \mathrm{~g}$ and Level 2 gowns $\leq 1 \mathrm{~g}$ (Table 1). The mean change in blotter paper weight $(\mathrm{g})$ for cuffs was compared to the ANSI/AAMI PB70 classification requirements for critical zones of gowns. The number of gown cuffs per sample group with a low change in blotter paper weight sufficient to meet the ANSI/AAMI PB70 classification criteria are listed in Table 7. Groups with no cuffs meeting the criteria were omitted from Table 7. As expected, most cuffs did not meet the criteria had they been considered critical zones. Only 20 out of the 96 (20.8\%) gown cuffs from claimed Level 1 gowns passed with a change in blotter paper weight $\leq 4.5 \mathrm{~g}$. Forty-three of the $96(44.8 \%)$ cuffs from claimed Level 2 gowns passed with a change in blotter paper weight $\leq 1 \mathrm{~g}$.

\subsection{AATCC 127-2013 Water Resistance: Hydrostatic Pressure Test Results}

An ANOVA and post hoc tests were performed on the pressure at the third water droplet penetration location (mbar) data from the water resistance penetration test.

Table 8. Descriptive statistics for number of washes, ANSI/AAMI liquid barrier classification level, and the interaction between them for the water pressure resistance test (AATCC 127-2013)

\begin{tabular}{lccc}
\hline \multicolumn{1}{c}{ Specimen Source } & n & $\begin{array}{c}\text { Mean Third Drop } \\
\text { Pressure (mbar) }\end{array}$ & SD \\
\hline Cuffs Washed 1 Time & 96 & 8.84 & 3.91 \\
Cuffs Washed Multiple Times & 96 & 6.09 & 3.29 \\
Cuffs from Level 1 Gowns & 96 & 7.42 & 4.99 \\
Cuffs from Level 2 Gowns & 96 & 7.51 & 2.24 \\
Cuffs from Level 1 Gowns Washed 1 Time & 48 & 8.61 & 5.19 \\
Cuffs from Level 1 Gowns Maximum Laundered & 48 & 6.24 & 4.53 \\
Cuffs from Level 2 Gowns Washed 1 Time & 48 & 9.07 & 1.97 \\
Cuffs from Level 2 Gowns Maximum Laundered & 48 & 5.94 & 1.13 \\
\hline
\end{tabular}


Table 8 shows the descriptive statistics for the water pressure resistance test. The mean third drop pressure (mbar) for cuffs washed multiple times $(M=6.09)$ was less than the mean for cuffs washed 1 time $(M=8.84)$. Cuffs from Level 1 gowns had a mean third drop pressure (mbar; $M=7.42$ ) that was almost equal to the mean for cuffs from Level 2 gowns $(M=7.51)$. Level 1 gown cuffs $(M=6.13)$ and Level 2 gown cuffs $(M=5.27)$ laundered to the maximum cycles allowed more water to penetrate the fabric than Level 1 gown cuffs ( $M=4.71)$ and Level 2 gown cuffs $(M=0.27)$ only washed once.

Table 9. LSMeans Student t-test results for water pressure resistance testing (AATCC 127-2013)

\begin{tabular}{ll}
\hline \multicolumn{1}{c}{ Comparison } & $p$-Value \\
\hline Level 1 vs Level 2 & 0.87 \\
Washed Once vs Max Laundered & $<0.0001$ \\
\hline
\end{tabular}

The LSMeans Student's t-test shows that the only significant difference was between number of washings $(p<0.0001)$ with gowns washed one time $(M=8.84)$ having a higher mean third drop pressure (mbar) than gowns washed multiple times ( $M=6.09$ ). There was no significant difference ( $p>0.05)$ between cuffs from gowns claimed as Level $1(M=7.42)$ and Level $2(M=7.51)$. 
Table 10. LSMeans Tukey HSDresults for water pressure resistance testing (AATCC 127-2013) for sample gown comparisons within each ANSI/AAMI PB70 level

\begin{tabular}{lc}
\hline \multicolumn{1}{c}{ Comparison } & p-Value \\
\hline Sample Gown B vs Sample Gown F (within Level 1) & 1.00 \\
Sample Gown B vs Sample Gown H (within Level 1) & 0.99 \\
Sample Gown F vs Sample Gown H (within Level 1) & 0.99 \\
Sample Gown A vs Sample Gown C (within Level 2) & 0.86 \\
Sample Gown A vs Sample Gown D (within Level 2) & 0.89 \\
Sample Gown C vs Sample Gown D (within Level 2) & 1.00 \\
\hline
\end{tabular}

The LSMeans Tukey HSD test (Table 10) revealed that within the Level 1 claimed classification, cuffs from sample gowns $B, F$, and $H$ performed similar ( $p>0.05$ ). All 3 cuffs from sample gowns A, C, and D within the Level 2 claimed classification performed similar as well (no significant difference, $p>0.05$ ).

Table 11. ANOVA results from JMP (SAS, Cary, NC) for the water pressure resistance test (AATCC 127-2013)

\begin{tabular}{lcccc}
\hline \multicolumn{1}{c}{ Source } & $\begin{array}{c}\text { Degrees of } \\
\text { Freedom }\end{array}$ & $\begin{array}{c}\text { Sum of } \\
\text { Squares }\end{array}$ & F Ratio & Prob > F \\
\hline AAMI PB70 Claimed Level & 1 & 0.33 & 0.03 & 0.87 \\
Number of Times Washed & 1 & 363.55 & 27.31 & $<0.0001$ \\
$\begin{array}{l}\text { Sample Gowns nested within AAMI } \\
\text { PB70 Claimed Level }\end{array}$ & 4 & 26.68 & 0.50 & 0.74 \\
$\begin{array}{l}\text { AAMI PB70 Claimed Level crossed } \\
\text { with Number of Times Washed }\end{array}$ & 1 & 6.90 & 0.52 & 0.47 \\
\hline
\end{tabular}

The only difference not likely due to chance was the difference between number of washings on the third drop pressure (mbar) $(p<0.0001)$ (Table 10). 
Critical zones of gowns claimed as Level 2 can only have a third drop pressure no less than $20 \mathrm{~cm} \mathrm{H}_{2} \mathrm{O}$ (19.61 mbar) for critical zones according to ANSI/AAMI PB70 (Table 1). Gowns claimed to be Level 1 by manufacturers do not have to meet the requirements for the water pressure resistance test according to ANSI/AAMI PB70. The mean third drop pressure for cuffs was compared to the AAMI/ANSI PB70 classification requirements for critical zones of gowns. None of the cuffs meet the criteria had they been considered critical zones. The highest pressure reached was $16.7 \mathrm{mbar}$ (from sample group $\mathrm{H}$ washed once). Had the cuffs been considered as part of the critical zone for the isolation gowns according to ANSI/AAMI PB70, all cuffs from claimed Level 2 gowns would not have been eligible to be claimed as Level 2 . 


\section{CHAPTER 4: DISCUSSION}

As a reminder, the research questions and hypotheses were as follows:

\section{The research questions were:}

- Do the cuffs meet the liquid barrier performance criteria expected for the ANSI/AAMI level claimed by the manufacturer for the rest of the gown?

- Does washing the gown cuffs to the maximum recommended number of cycles, reduce the liquid barrier performance compared to gown cuffs washed once?

- Do sample gowns within each ANSI/AAMI classification level provide the same liquid barrier performance?

\section{The main hypotheses were:}

- Gown cuffs from gowns within the ANSI/AAMI PB70 Level 2 classification will have significantly higher liquid barrier performance than the gown cuffs from gowns in the Level 1 classification.

- Cuffs from sample gowns claimed to be Level 1 will not meet the liquid barrier performance criteria required for critical zones.

- Cuffs from sample gowns claimed to be Level 2 will not meet the liquid barrier performance criteria required for critical zones.

- Gown cuffs washed to the maximum recommended number of laundering cycles will have decreased liquid barrier performance compared to cuffs only washed once

- Sample gown cuffs $B, F$, and $H$ will have significantly different barrier performance within ANSI/AAMI PB70 Level 1.

- Sample gown cuffs $A, C$, and D will have significantly different barrier performance within ANSI/AAMI PB70 Level 2. 


\subsection{Cuff barrier performance between ANSI/AAMI PB70 claimed levels of protection}

In the water impact penetration test (AATCC 42-2015), there was an expected significant difference between Level 1 and Level 2. Level 2 gowns allowed less water to penetrate through the cuff material than Level 1 gown cuffs. In the water pressure resistance test (AATCC 127-2013), all gown cuffs performed similarly, meaning there was no difference in barrier performance between Levels 1 and 2 . This was not as expected.

There is not sufficient evidence to support the hypothesis that gown cuffs from gowns within the ANSI/AAMI PB70 Level 2 classification will have significantly higher liquid barrier performance than the gown cuffs from gowns in the Level 1 classification. Depending on the task, cuffs from a Level 2 gown may perform more similar to a Level 1 gown. This has serious implications for the user because depending on amount of bodily fluids and the presence of infectious disease, the user could be put at risk for exposure.

\subsection{Cuffs from claimed Level 1 and 2 liquid barrier performance compared to criteria required for critical zones}

Both Level 1 and Level 2 gowns must pass the pass/fail criteria (Table 1) for the water impact penetration test (at different specified values) in order to be claimed as such (AATCC 42-2015). Only 20 out of the 96 (20.8\%) Level 1 gowns passed with a change in blotter paper weight $\leq 4.5 \mathrm{~g}$ for the water impact test. Forty-three of the 96 $(44.8 \%)$ Level 2 gown cuffs passed with a change in blotter paper weight $\leq 1 \mathrm{~g}$. Only gown cuff groups $\mathrm{C}$ and $\mathrm{H}$ completely passed the water impact penetration test.

Only Level 2 gowns must pass the water pressure resistance test (AATCC 1272013) (Table 1). None of the gown cuffs from gowns claiming to be Level 2 reached the required pressure level of $19.61 \mathrm{mbar}$ (Table 1) for the water pressure resistance test.

Most of the cuffs failed the pass/fail criteria for these tests indicating that if a person had been wearing the gown, they would have potentially not have been 
protected to the claimed level. In a healthcare setting, up to 4 out of 5 Level 1 gown cuffs could allow enough penetration that the user would experience contamination and thus be put at risk for infection. Almost half of Level 2 gown cuffs could also experience the same risk.

These findings are in agreeance with findings from a study by Balci et al. (2015) on disposable gowns. Disposable gowns have been found to not meet the criteria set by ANSI/AAMI PB70 for the levels claimed by the manufacturers. This has negative implications for end users trying to purchase gowns with a certain level of protection, as they may falsely believe they are being protected when they are not.

\subsection{Cuff barrier performance between number of washings}

In the water impact penetration test (AATCC 42-2015), the mean number of washings was significant $(p<0.0001)$ with gowns washed once allowing less water to penetrate through the fabric to wet the blotter paper than gowns washed multiple times. In the water pressure resistance test (AATCC 127-2013), the only parameter with significant differences in the means was between number of washings $(p<0.0001)$ with gown cuffs washed once providing slightly more protection to water penetration at a higher pressure versus gown cuffs washed multiple times.

The findings of this study are in agreeance with previous research, in that the data also shows newer gown cuffs perform better than those that have been washed multiple times (Telford and Quebbemen, 1993; Smith et al, 1991). These findings may help manufacturers determine their specific recommendations when assigning the maximum recommended number of laundering cycles for reusable isolation gowns.

\subsection{Cuff barrier performance within ANSI/AAMI PB70 claimed Level 1 protection}

When looking at gowns $\mathrm{B}, \mathrm{F}$, and $\mathrm{H}$ within the Level 1 classification for the water impact penetration test (AATCC 42), all the gowns performed similar, except for sample group H. Gown H cuffs didn't perform similar to either Level 1 gown cuffs or Level 2 (Figure 3). This is likely due to the multi-washed group $\mathrm{H}$ gowns being washed 25 more 
times than any other of the multi-washed gowns. This agrees with the hypothesis that each sample gown cuff group would perform differently within each level.

For the water pressure resistance test (AATCC 127-2013), all gown types performed similarly $(p>0.05)$. Level 1 gowns do not need to meet the water pressure resistance criteria set by ANSI/AAMI PB70. Results from this test are not in support of the hypothesis that the different sample groups within Level 1 would perform differently.

Considering that group $\mathrm{H}$ had been washed so many more times than the other Level 1 gowns, there is not sufficient evidence to support the hypothesis that the sample gown groups within each claimed level have different barrier capabilities.

\subsection{Cuff barrier performance within ANSI/AAMI PB70 claimed Level 2 protection}

All level 2 gown cuffs (A, C, D) performed very similar for the water impact penetration test (AATCC 42-2015), which disagrees with the hypothesis that there would be a difference in the means within each level.

For the water pressure resistance test (AATCC 127-2013), all gown types performed similarly $(p>0.05)$, with all gowns failing the pass/fail criteria. This also disagrees with the hypothesis that each sample gown cuff group would perform differently within each level.

\subsection{Future Use}

Future studies should consider repeating the modified methods for the water pressure resistance test (AATCC 127-2013) in this paper but also modifying the rate at which the pressure increases. The rate of $60 \mathrm{mbar} / \mathrm{min}$ may have been too aggressive since none of the data passed $16.7 \mathrm{mbar}$, which is less than the pass/fail criteria for Level 2 gown critical zones (i.e. $19.61 \mathrm{mbar}$ ). Slowing the rate may help the user to respond quicker to the first, second, and third drop appearances. This would also allow for more accurate data analysis since the operator's reaction time would more accurately represent the first, second, and third water penetration appearance. 
A similar study to this should be performed on disposable gown cuffs. However, it should be considered that the cuff designs for disposable gowns are significantly different than cuff designs for reusable gowns. Disposable gowns mainly designed using an elastic type of cuffs or cuffs with thump loops. In both of the types, in general the same type of fabric material that is used for the body of the gown is used for the cuff. Therefore, the barrier protection level of cuffs could be similar to the barrier protection level of the cuffs. Also, since there is no other fabric attached to the sleeves for cuff attachment, seams are not used which could be considered as an advantageous for barrier protection. It should be noted that a small area is used for the attachment of the elastic material to the sleeves. Similar to reusable gown cuffs, little information exists on the barrier capabilities of disposable gown cuffs.

A study examining the effect of water temperature on fabric permeability should be conducted. Limited research exists on the effect of water temperature on permeability properties of fabric. The test should be conducted using a fabric with a known, constant permeability while using a constant amount of water at various temperatures during the same test. Water in the current study couldn't be conditioned to the recommended temperatures listed within the standards. While the water temperature was never more or less than $5^{\circ} \mathrm{C}$ from the recommended temperature, it cannot be assumed that this small of a change had no effect on the test outcomes.

Lastly, a study should be performed to examine various numbers of cycles of washing and drying on the barrier properties of isolation gown cuffs. This study only examined the minimum and maximum recommended laundering cycles. Several cycles between the two (such as 25, 50, and 75 times) should be examined.

Findings in this study will contribute to other barrier effectiveness data that will be used in future design assessment and performance criteria for recommendations/standards. The data could potentially contribute to the development of performance and design requirements that manufacturers can use to improve isolation gown design. This information will contribute to better designed gowns that will help prevent skin exposure to infectious diseases for HCWs. Better designed gowns may help to reduce the large amount of unnecessary annual deaths and associated 
medical costs (Shannon, 2011). The findings of this study could help to provide useful information to the end user who determines which gown is most appropriate for the intended task (ANSI/AAMI, 2012). 


\section{CHAPTER 5: CONCLUSION}

Isolation gown cuffs are known to have contamination and penetration issues, even when users are compliant with donning and doffing procedures. Overall, the isolation gown cuffs in this study did not meet required liquid barrier performance criteria compared to ANSI/AAMI PB70 classification requirements for critical zones of isolation gowns. Gowns that are washed multiple times have reduced barrier effectiveness compared to new gowns. This combined with Rutala and Weber (2001) finding that the lifespan of gowns is reduced up to $50 \%$ with routine use, the maximum number of laundering cycles may need to be adjusted. The findings of this study should be used in the future development of design assessment and performance criteria standards. Manufacturers can use the findings to better design isolation gowns in order to protect HCWs from the risk of exposure to infectious diseases like HIV and Ebola virus.

\section{Limitations}

The first limitation to this study is that there are no studies that exist that examine the barrier properties of gown cuffs. Therefore, there is no data to which the results of this study can be compared. While cuffs are not considered a critical zone, it is important to note that the cuffs can be exposed to blood and bodily fluids during certain tasks. Isolation gown cuffs are not required to be made of the same materials as the critical zones. Therefore, different materials with varying barrier effectiveness are used (Kilinc, 2015). Some of the most common areas found to be contaminated with blood on isolation gowns were the cuffs, forearms, thighs, chest, and abdomen (Goldfrank \& Liverman, 2007). There are also leakage and contamination issues known to the gown/glove interface (Goldfran\& Liverman, 2007; Telford \& Quebbeman, 1993; Zachary et al., 2001). Even though this information is known, no studies exist that examine the barrier properties of gown cuffs.

One minor limitation to the study was that distilled water for each test was to be conditioned and used at a specific temperature. The laboratory did not have the capability to condition water, so distilled water was used at the temperature the water is 
dispensed, which was never more than $5^{\circ} \mathrm{C}$ different from the required temperature for each standard.

A major limitation to this study was the limited scope. Only 6 gown types were available for testing. There is a small number of types and manufacturers of isolation gowns on the market. More limiting is that there were only two ANSI/AAMI PB70 levels to examine. However, no isolation gowns were found on the U.S. market with ANSI/AAMI PB70 Level 3 and 4 claims. All Level 2 gowns had been made by the same manufacturer. The available specimen number size $(n=16)$ was small. Had more gowns, gown types and levels been available, a more thorough study could have been performed. Thus, the findings are limited to these specific types of reusable isolation gowns and may not accurately represent other manufacturers.

The major limitation to the water penetration resistance test (AATCC 127-2013) was operator reaction time. The water penetrated the cuffs in three unique locations in such quick succession that the test couldn't be stopped quick enough to accurately represent all three penetration locations. The first drop pressure was likely a better representation of operator reaction time but the third drop pressure had to be used in order to compare the data to the ANSI/AAMI PB70 standard. Slowing the $60 \mathrm{mbar} / \mathrm{min}$ pressure rate to something slower may allow for better response time and thus more accurate readings.

Lastly, when performing data analysis, the maximum number of washings for $\mathrm{H}$ was changed to match the others at 75 cycles. Instead of taking into consideration $\mathrm{H}$ was washed to a different number of cycles, all were viewed as the "maximum recommended cycles". It is suspected that any differences from the other two groups (B and $F$ ) within Level 1 were because of the difference in number of maximum laundering cycles used. Group $\mathrm{H}$ was manufactured by a different company than the shared manufacturer of both $B$ and $F$ which could have also contributed to the differences. However, this is speculation and would require further testing to confirm.

The information gathered in this study will need to be used in conjunction with proper donning and doffing of other PPE such as gloves. Any misuse of PPE will cause higher exposure risk. According to ANSI/AAMI PB 70:2012, blood can penetrate 
through most fabrics more readily than water due to the high surface tension of water. Thus, if a gown passes these tests at the appropriate level, the gown may not protect against blood/bodily fluid strike-through. With a single drop of blood potentially containing thousands of blood-borne pathogens (Ahmad et al., 1998), further testing for the ability for blood and bodily fluids to migrate from one side of protective apparel to the other should be conducted. 


\section{BIBLIOGRAPHY}

American Association of Textile Chemists and Colorists (2013). Water resistance:

Hydrostatic pressure test. AATCC 127. Research Triangle Park (NC): AATCC.

American Association of Textile Chemists and Colorists (2015). Water resistance: Impact penetration test. AATCC 42. Research Triangle Park (NC): AATCC.

Agbayani, M., Rosenfeld, W., Evans, H., Salazar, D., Jhaveri, R., and Braun, J. (1981). Evaluation of modified gowning procedures in a neonatal intensive care unit. Am J Dis Child, 135: 650-652.

Ahmad, F.K., Sherman, S.J., and Hagglund, K.H. (1998). The Use and Failure Rates of Protective Equipment to Prevent Blood and Bodily Fluid Contamination in the Obstetric Health Care Worker. Obstetrics and Gynecology, 92(1): 131-136.

AAMI (2015). FDA Releases Guidance Outlining Premarket Approval of Healthcare Gowns. Accessed from: http://www.aami.org/newsviews/newsdetail.aspx?ltemNumber=2952. Accessed Nov. 2016.

ANSI-AAMI (2012). Liquid Barrier Performance and Classification of Protective Apparel and Drapes Intended for Use in Health Care Facilities. ANSI/AAMI PB70:2012, Association for the Advancement of Medical Instrumentation. Arlington, VA: AAMI.

ASTM INTERNATIONAL (2016). Standard Practice for Conditioning and Testing Textiles. ASTM D1776/D1776M. West Conshohocken (PA): ASTM International.

Balci, F.S.K. (2016). Isolation gowns in health care settings: Laboratory studies, regulations and standards, and potential barriers of gown selection and use. American journal of infection control, 44.1: 104-111.

Balci, F.S.K. (November 29, 2016). Personal Communication. 
Balci, F.S.K. and D'Alessandro, M. (2015). NIOSH Research Highlights Importance of Rigorous Standards for Gowns Used to Protect Healthcare Workers. NIOSH Science Blog. Accessed from: https://blogs.cdc.gov/niosh-scienceblog/2015/07/22/isolation-gowns/ (Accessed October 2016).

Balci, F.S.K., Nwoko, J., and Hillam, T. (2015). Evaluation of the Performance of Isolation Gowns. American Journal of Infection Control, 43: S18-S73.

Bureau of Labor Statistics (2015). Table 1. National employment and wage data from the Occupational Employment Statistics survey by occupation, May 2015. Retrieved from: http://www.bls.gov/news.release/ocwage.t01.htm (Accessed October 2016).

Belkin, N.L. (2000). Testing Surgical Gowns for the "Anticipated Level of Exposure". Journal of Laparoendoscopic \& Advanced Surgical Techniques, 10(2): 119-122.

Belkin, N.L. (2002). A Historical Review of Barrier Materials. AORN Journal, 76(4): 648653.

Birenbaum, H.G., Glorioso, L., Rosenberger, K.C., Arshad, C., and Edwards, K.(1990). Gowning on a postpartum ward fails to decrease colonization in the newborn infant. Am J Dis Child, 144:1031-1033.

Caron 6010 Series Environmental Chamber. 2012. Marietta, OH. Caron Products and Services, Inc.

Food and Drug Administration [FDA] (2015). Premarket Notification Requirements Concerning Gowns Intended for Use in Health Care Settings. Accessed from: http://www.fda.gov/downloads/MedicalDevices/DeviceRegulationandGuidance/G uidanceDocuments/UCM452804.pdf?source=govdelivery\&utm medium=email\&u tm source=govdelivery. Accessed September 2016.

Goldfrank, L.R., and Liverman, C.T., eds. (2007). Preparing for an Influenza Pandemic: Personal Protective Equipment for Healthcare Workers. Washington, DC: National Academies Press. 
Granzow, J.W., Smith, J.W., Nichols, R.L., Waterman, R.S., and Muzik, A.C. (1998).

Evaluation of the protective value of hospital gowns against blood strike-through and methicillin-resistant Staphylococcus aureus penetration. Am J Infect Control, 26(2): 85-93.

Gruendemann, B. (2002). Single use vs. Reusable Gowns and Drapes. Infection Control Today, 6(3). Accessed from:

http://www.infectioncontroltoday.com/articles/2002/03/taking-cover.aspx (Accessed October 2016).

Holguin M., "Standard Precautions for Healthcare Workers and the Role of Isolation Gowns, Education \& Training, http://healthvie.com Jan 2011.

Kilinc, F.S. (2015). A Review of Isolation Gowns in Healthcare: Fabric and Gown Properties. Journal of Engineered Fibers and Fabrics, 10(3): 180-190. Accessed from: http://www.jeffjournal.org/papers/Volume10/V10|3(20)\%20F.\%20Kilinc.pdf (Accessed October 2016).

Klein, E., Smith, D.L., and Laxminarayan, R. (2007). Hospitalizations and deaths caused by methicillin-resistant Staphylococcus aureus, United States, 19992005. Emerg Infect Dis. Available from http://wwwnc.cdc.gov/eid/article/13/12/070629 (Accessed Oct 2016).

Knitting (2016).Textile School. Retrieved from: http://www.textileschool.com/articles/171/knitting.

Knit Fabrics (n.d.). Utah Education Network. Accessed from http://www.uen.org/cte/family/clothing-2/downloads/textiles/knit.pdf. (Accessed October 2016).

Laufman, H., Eudy, W.W., Vandernoot, A.M., Liu, D. and Harris, C.A. (1975). Strikethrough of Moist Contamination by Woven and Nonwoven Surgical materials. Am. Surg., 857-862. 
Leonas, K.K. (2005). Chapter 16: Microorganism protection. Textiles for protection, Woodhead Publishing-CRC Press, Boca Raton, FL USA. 441-464.

Lovitt, S.A., Nichols, R.L., Smith, J.W., Muzik, A.C, and Pearce, P.F., (1992). Isolation gowns: A false sense of security? AJIC Am J Infect Control, 20: 185-191.

National Institute for Occupational Safety and Health [NIOSH] (2016). Considerations for Selecting Protective Clothing used in Healthcare for Protection against Microorganisms in Blood and Bodily Fluids. Retrieved from: http://www.cdc.gov/niosh/npptl/topics/protectiveclothing/default.html (Accessed October 2016).

Occupational Safety \& Health Administration [OSHA]. (2012). Bloodborne Pathogens (Standards-29 CFR 1910.1030). Retrieved from https://www.osha.gov/pls/oshaweb/owadisp.show_document?p_table=standards $\& p \_i d=10051$ (Accessed October 2016).

Renaud, M.T. (1983) Effects of discontinuing cover gowns on a postpartal ward upon cord colonization for the newborn. JOGN Nurs, 12: 399-401

Rutala, W.A. and Weber, DJ. (2001). A review of single-use and reusable gowns and dapes in health care. Infection Control and hospital Epidemiology, 22(4): 248257.

SAS Institute Inc. 2015. Using JMP 12. Cary, NC: SAS Institute Inc.

Sepkowitz, K.A., and Eisenberg, L. (2005). Occupational Deaths among Healthcare Workers. Emerging Infectious Diseases, 11(7): 1003-1008.

Shannon, R.P. (2011). Eliminating Hospital Acquired Infections: Is It Possible? Is It Sustainable? Is It Worth It? Transactions of The American Clinical And Climatological Association, 122: 103-114.

Siegel, J.D., Rhinehart, E., Jackson, M., Chiarello, L., and the Healthcare Infection Control Practices Advisory Committee, (2007). Guideline for Isolation 
Precautions: Preventing Transmission of Infectious Agents in Healthcare Settings. Center for Disease Control (CDC).

Slater, K. (1998). Textile use in surgical gown design. Canadian Textile Journal, 8: 1618.

Smith, J.W. and Nichols, R.L. (1991). Barrier Efficiency of Surgical Gowns. Arch Surg, 126: 756-763.

Telford, G.L. and Quebbeman, E.J. (1993). Assessing the risk of blood exposure in the operating room. AJIC Am J Infect Control, 21: 351-356.

Zachary, K.C., Bayne, P.S., Morrison, V.J., Ford, D.S., Silver, L.C., and Hooper, D.C. (2001). 